\title{
Origin of Stereoselectivity in FLP-Catalyzed Asymmetric Hydrogenation of Imines
}

\section{Hamza, Andrea}

2020-12-04

Hamza , A , Sorochkina , K, Kotai , B , Chernichenko , K, Berta , D , Bolte , M , Nieger , M , Repo , T \& Papai , I 2020 , ' Origin of Stereoselectivity in FLP-Catalyzed Asymmetric Hydrogenation of Imines ' , ACS catalysis , vol. 10 , no. 23 , pp. 14290-14301 . https://doi.org/10.1021/acscatal.0c04

http://hdl.handle.net/10138/326202

https://doi.org/10.1021/acscatal.0c04263

cc_by

publishedVersion

Downloaded from Helda, University of Helsinki institutional repository.

This is an electronic reprint of the original article.

This reprint may differ from the original in pagination and typographic detail.

Please cite the original version. 


\title{
Origin of Stereoselectivity in FLP-Catalyzed Asymmetric Hydrogenation of Imines
}

\author{
Andrea Hamza, ${ }^{\S}$ Kristina Sorochkina, ${ }^{\S}$ Bianka Kótai, Konstantin Chernichenko, Dénes Berta, \\ Michael Bolte, Martin Nieger, Timo Repo,* and Imre Pápai*
}

Cite This: ACS Catal. 2020, 10, 14290-14301

Read Online

\section{ACCESS}

山ll Metrics \& More

Article Recommendations

Supporting Information

ABSTRACT: Development of metal-free strategies for stereoselective hydrogenation of unsaturated substrates is of particular interest in asymmetric synthesis. The emerging chemistry of frustrated Lewis pairs offers a promising approach along this line as demonstrated by recent achievements. However, the stereocontrol elements in these reactions are not clearly recognized thus far. Herein, we analyze the origin of stereoinduction in direct hydrogenation of imines catalyzed by a set of chiral boranes. We use the tools of computational chemistry to describe the elementary steps of the catalytic cycle, and we pay special attention to the stereoselectivity-determining hydride transfer process. The
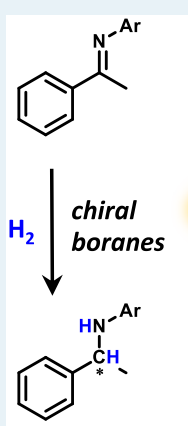

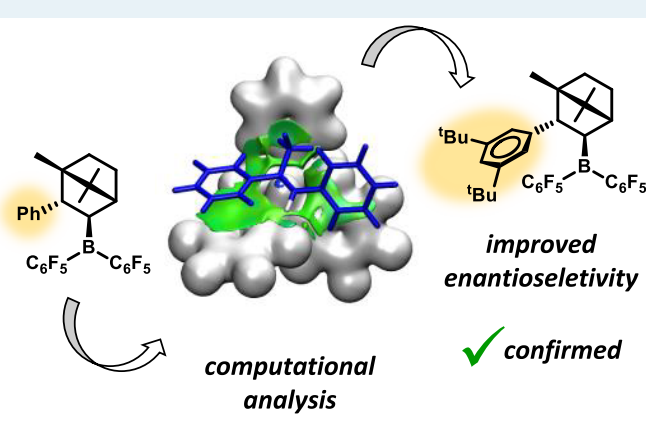
enantioselectivities predicted by the applied computational approach are in very good agreement with previous experimental observations. We find that the stereoselectivity is governed by a thermodynamically less favored conformer of the borohydride intermediate and not by the experimentally observed form. The most favored hydride transfer transition states are stabilized by specific aryl-aryl and alkyl-aryl noncovalent interactions, which play an important role in stereoinduction. This computational insight is exploited in proposing additional borane variants to improve the enantioselectivity, which could be demonstrated experimentally

KEYWORDS: frustrated Lewis pairs, asymmetric hydrogenation, mechanism, stereocontrol, DFT

\section{INTRODUCTION}

Chiral amines, particularly those bearing $\alpha$-stereogenic carbon atoms, are widely used intermediates in the production of pharmaceuticals, agrochemicals, and fine chemicals. Therefore, the development of effective methods for enantioselective synthesis of these compounds is of high interest. ${ }^{1}$ Among the available synthetic strategies, the asymmetric hydrogenation of prochiral imines and enamines by the direct use of $\mathrm{H}_{2}$ as the hydrogen source represents a promising atom-economic approach. $^{2}$ A variety of transition metal (TM) complexes comprising chiral organic ligands have been developed, and some of them have proved to be efficient catalysts for direct enantioselective imine hydrogenations. Iridium complexes are known to be particularly powerful hydrogenation catalysts; however, achieving very high enantioselectivities for a wide range of substrates remains challenging. ${ }^{3}$

Metal-free routes to the synthesis of chiral amines via catalytic hydrogenation have also been developed in the past decade. ${ }^{4}$ Several successful organocatalytic transfer hydrogenation reactions catalyzed by chiral phosphoric acids as well as hydrosilylations mediated by chiral Lewis bases have been reported, but these transformations require a stoichiometric amount of other hydrogen sources, such as Hantzsch ester or trichlorosilane..$^{5}$ The discovery that sterically hindered Lewis acid-base pairs are able to cleave molecular hydrogen reversibly under mild reaction conditions ${ }^{6}$ opened a metal-free strategy for direct catalytic hydrogenation of unsaturated molecules. ${ }^{7}$ These so-called frustrated Lewis pairs (FLPs) ${ }^{8}$ were shown to catalyze various unsaturated organic substrates ${ }^{9}$ even under watertolerant conditions. ${ }^{10}$

The FLP concept has been successfully adopted to design asymmetric catalytic hydrogenation processes as well. ${ }^{11}$ Pioneering contributions from Klankermayer et al. ${ }^{12}$ provided the first examples of chiral induction by FLPs. Boranes 1-4 (Chart 1) were prepared via hydroboration of chiral olefins with Piers' borane $\left(\mathrm{C}_{6} \mathrm{~F}_{5}\right)_{2} \mathrm{BH},{ }^{13}$ and they were employed for the hydrogenation of imines. The $(+)$ - $\alpha$-pinene derived borane 1 gave only a low enantiomeric excess (ee) in the product amine ( $13 \%$ ee $){ }^{12 a}$ however, the asymmetric induction was notably improved (up to $83 \%$ ee) using boranes $2-4$, which were derived from $(1 R)-(+)$-camphor. ${ }^{12 b}$

Received: September 30, 2020

Revised: October 30, 2020

Published: November 23, 2020 
Chart 1. Selection of Chiral FLP Components Employed in Enantioselective Catalytic Hydrogenations ${ }^{a}$
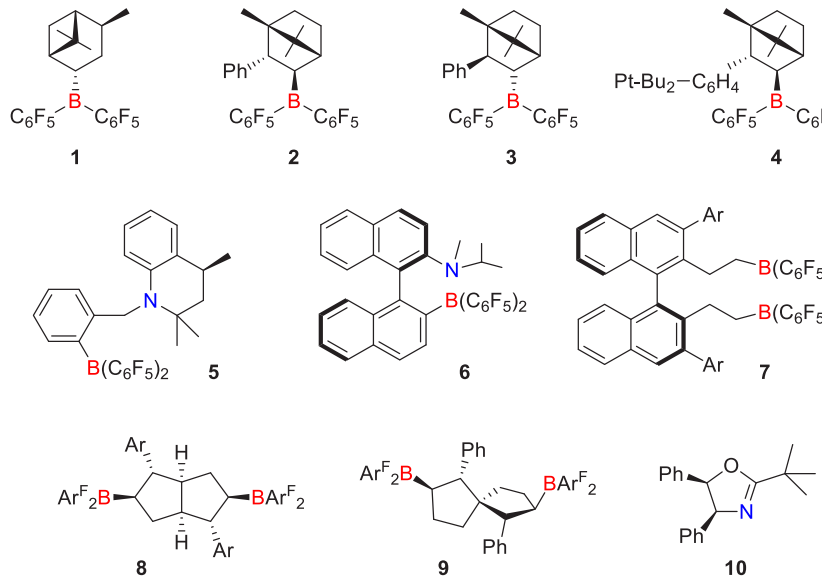

10
${ }^{a}$ Ar denotes aromatic substituents; $\operatorname{Ar}^{\mathrm{F}}=\mathrm{C}_{6} \mathrm{~F}_{5}$ or $p-\mathrm{C}_{6} \mathrm{~F}_{4} \mathrm{H}$.

Repo and co-workers developed intramolecular FLPs with chiral amine moieties (e.g., 5); however, they resulted in only moderate enantioselectivities in catalytic hydrogenation of imines and quinolines (up to $37 \%$ ee). ${ }^{14}$ The same group later introduced chirality via the binaphthyl framework into ansaaminoboranes, and intramolecular FLP 6 was shown to be an efficient hydrogenation catalyst, particularly for asymmetric hydrogenation of enamines (ee values up to $99 \%$ ). ${ }^{15}$ In 2013, Du proposed a simple and powerful strategy to generate enantiomerically pure bis-boranes 7 in situ by direct hydroboration of binaphthyl-based terminal dienes. ${ }^{16}$ Some representatives of this family of chiral boranes, especially those with very bulky Ar substituents on the binaphthyl framework, were demonstrated to be highly effective catalysts in enantioselective hydrogenation of imines, ${ }^{16}$ silyl enol ethers, ${ }^{17}$ and various heteroarenes $^{18}$ as well. Wang and co-workers have recently developed a series of $C_{2}$-symmetric bicyclic bis-boranes derived from cis-fused bicyclic dienes by hydroboration. ${ }^{19}$ Stereoisomer $\mathbf{8}$ of this series was found to be exceptionally efficient for imine hydrogenation providing ee's above $90 \%$ for the first time. In subsequent work, spiro-bicyclic bis-boranes 9 were also introduced, ${ }^{20}$ exhibiting excellent catalytic activities and stereoselectivities for the hydrogenation of quinolines and 2vinylpyridines. Attempts to control the stereochemistry of FLP-type hydrogenation by chiral Lewis bases resulted in only modest enantioselectivities, ${ }^{9 b}$ until a very recent study reported by the Du group, ${ }^{21}$ which established this approach as a promising direction for the design of new chiral FLPs. Quite remarkably, chiral oxazolines such as $\mathbf{1 0}$, combined with achiral boranes were shown to induce high degree of enantioselectivity in asymmetric hydrogenation of ketones and enones. In addition to direct catalytic hydrogenation, FLP-type asymmetric hydrosilylation has also been successfully applied to reduce various unsaturated substrates with high enantioselectivities. ${ }^{22}$

Despite these impressive advances, our knowledge regarding the stereocontrol elements in FLP-catalyzed asymmetric hydrogenation processes is quite scanty. So far, only a few computational studies have been reported that supplemented the synthetic developments and addressed the issue of stereoselectivity. ${ }^{15,21,23}$ Density functional theory (DFT) calculations carried out for the highly selective enamine hydrogenation with catalyst 6 indicated that the energy difference obtained for the hydride transfer transition states leading to the two enantiomeric amine products stems from a combination of repulsive steric and attractive noncovalent interactions. ${ }^{15}$ The stereoselectivity determining transition states for asymmetric hydrogenation of ketones catalyzed with the $\mathrm{B}\left(p-\mathrm{C}_{6} \mathrm{~F}_{4} \mathrm{H}\right)_{3} / 10$ pair were also identified computationally. ${ }^{21}$ The predicted energy differences were consistent with experimental observations, but the origin of stereoinduction was not examined.

To gain more insight into the nature of molecular interactions responsible for the stereoselectivity of FLP-catalyzed hydrogenation, in our present work we investigated a reaction that is frequently used as a test case in the evaluation of developed catalysts, namely, the direct hydrogenation of imine (E)-N-(1phenylethylidene)-aniline (im, see Scheme 1). As shown

Scheme 1. Reactions Examined Computationally

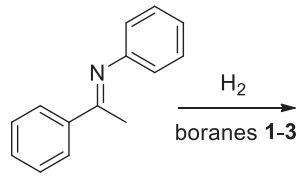

im

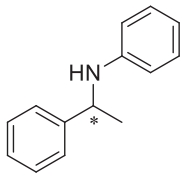

am observed enantioselectivities:

1: $13 \%$ ee $(R)$

2: $79 \%$ ee $(R)\left(\right.$ base $\left.=\mathrm{P}^{\mathrm{t}} \mathrm{Bu}_{3}\right)$

3: $48 \%$ ee $(S)\left(\right.$ base $\left.=\mathrm{P}^{\mathrm{t}} \mathrm{Bu}_{3}\right)$ previously, the enantioselectivity of this reaction varies in a fairly broad range (from poor to good) when structurally analogous boranes $\mathbf{1}-\mathbf{3}$ are applied as catalysts; thus, this series of reactions allows us to inspect the effect of a single chiral borane substituent on the stereochemical outcome of the hydrogenation process.

In this work, we focus primarily on the stereoselectivitydetermining hydride transfer step of these reactions; however, for borane 2, we provide a detailed analysis of the $\mathrm{H}_{2}$ activation process as well. We closely inspect the conformational space of the iminium borodyride species, which is a key intermediate prior to product formation. Accurate prediction of stereoselectivities from quantum chemical calculations is rather challenging. ${ }^{24}$ In our present analysis, we attempted to pay respect to the critical issues (e.g., conformational complexity, the choice of the electronic structure method, estimation of entropic contributions, and solvent effects), and computed the enantioselectivity of the examined reactions accordingly (for computational details, see the Supporting Information (SI)). The good agreement obtained between the predicted and observed stereoselectivities allowed us to probe the origin of stereoinduction in these reactions. Based on the new computational insights, structural modifications in borane $\mathbf{2}$ were proposed, and two of these new chiral boranes were synthesized and tested as catalysts in asymmetric hydrogenation of imines.

\section{RESULTS}

Alternative Catalytic Cycles. As described by Klankermayer et al., ${ }^{12 \mathrm{~b}}$ the camphor-derived boranes 2 and 3 could not be isolated in pure stereoisomeric forms; however, kinetically controlled product formation in the reaction of the $2 / 3$ mixture with phosphine $\mathrm{P}^{t} \mathrm{Bu}_{3}$ (P) and $\mathrm{H}_{2}$ enabled isolation of diastereomerically pure ion pair compounds $\mathrm{PH}^{+} / 2 \mathrm{H}^{-}$and $\mathrm{PH}^{+} / 3 \mathrm{H}^{-}$. These phosphonium/hydroborate FLP salts were then used as catalysts in the hydrogenation of imines. In principle, the catalysis in these reactions can take place via two distinct cycles, as illustrated in Scheme 2.

In cycle 1 , the heterolytic $\mathrm{H}_{2}$ splitting is induced by the $\mathbf{P} / \mathbf{B}$ pair resulting in the $\mathrm{PH}^{+} / \mathrm{BH}^{-}$ion pair. Proton transfer from 
Scheme 2. Alternative Catalytic Cycles in Imine Reduction ${ }^{a}$

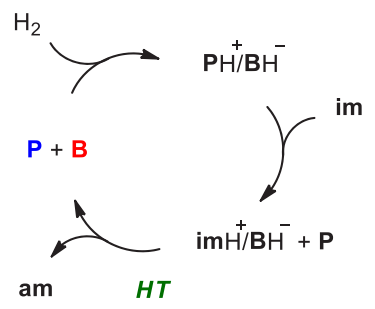

cycle 1: $H_{2}$ activation by $P / B$

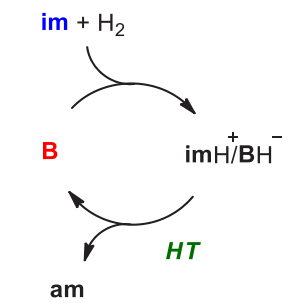

cycle $2: \mathrm{H}_{2}$ activation by $\mathrm{im} / \mathrm{B}$

${ }^{a}$ Notations: $\mathbf{P}$, im and am are defined in the text, $\mathbf{B}$ denotes chiral boranes $\mathbf{2}$ and 3. HT refers to hydride transfer from $\mathbf{B H}^{-}$to the prochiral carbon of $\mathrm{imH^{+ }}$.

$\mathbf{P H}^{+}$to im gives the $\mathrm{imH}^{+} / \mathrm{BH}^{-}$intermediate, which then undergoes hydride transfer (HT) to yield the chiral amine product am. Alternatively, the imine can serve as a base component of an FLP, so the $\mathrm{imH}^{+} / \mathrm{BH}^{-}$intermediate is formed directly via $\mathrm{H}_{2}$ activation (cycle 2 ). The HT process represents the stereoselectivity-determining step in both cycles. Our computational analysis suggests that cycle 2 is a more feasible pathway. DFT calculations carried out for the reaction with borane 2 predict a significantly higher barrier for $\mathrm{H}_{2}$ activation with the $\mathbf{P} / \mathbf{2}$ pair as compared to that with $\mathrm{im} / \mathbf{2}$ (19.9 versus $15.8 \mathrm{kcal} / \mathrm{mol}$; see Figure 1). ${ }^{25}$

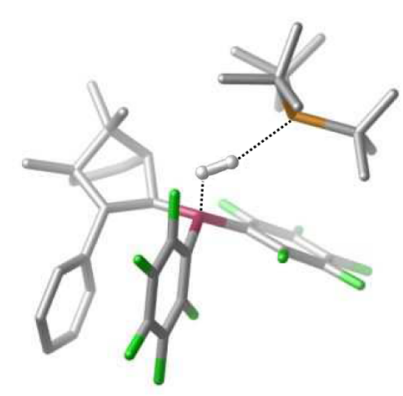

$\mathrm{TS}_{\mathrm{HH}}{ }^{\mathrm{P} / 2}(19.9)$

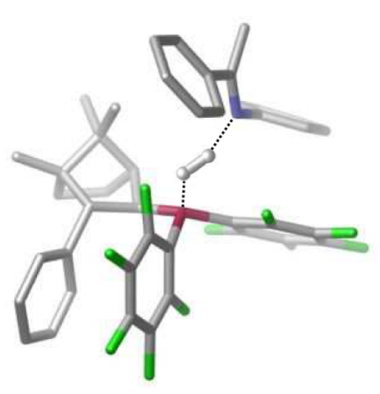

$\mathrm{TS}_{\mathrm{HH}}{ }^{\mathrm{im} / 2}(15.8)$
Figure 1. Transition states of $\mathrm{H}_{2}$ activation by the $\mathbf{P} / \mathbf{2}$ and $\mathrm{im} / \mathbf{2}$ FLPs. Relative stabilities (in $\mathrm{kcal} / \mathrm{mol}$, with respect to the base $+\mathbf{B}+\mathrm{H}_{2}$ reactant states) are given in parentheses. $\mathrm{H}$ atoms of the FLPs are omitted for clarity.

Even though $\mathrm{P}^{\mathrm{t}} \mathrm{Bu}_{3}$ is certainly more basic than imine im, ${ }^{26}$ steric hindrance between the chiral borane substituent and the bulky phosphine destabilizes the transition state of $\mathrm{H}_{2}$ splitting $\left(\mathrm{TS}_{\mathrm{HH}}{ }^{\mathrm{P} / 2}\right)$ leading to an increased barrier. Furthermore, the protonation of im on the $\mathbf{P} / \mathbf{2}$ pathway is computed to have even higher barrier $(31.6 \mathrm{kcal} / \mathrm{mol})$ rendering cycle 1 far less favorable. $^{27}$ Our calculations thus indicate that although the catalytic process in the hydrogenation of im is initiated by the $\mathrm{PH}^{+} / \mathbf{2} \mathrm{H}^{-}$ion pair, the catalysis follows the im/2 pathway. The high barrier obtained for the initiation step is consistent with the elevated temperature $\left(T=65^{\circ} \mathrm{C}\right)$ used in the experimental setup. $^{12 \mathrm{~b}}$

Iminium Borohydride Intermediates for Borane 2. The conformational space of the $\mathrm{imH}^{+} / \mathrm{BH}^{-}$intermediate formed upon $\mathrm{H}_{2}$ activation is rather complex because both ionic components can adopt different structures and their relative positions can vary as well. Conformations of borohydrides $\mathrm{BH}^{-}$ can be classified into three groups that differ in the orientation of the $\mathrm{B}-\mathrm{H}$ unit with respect to the chiral backbone (Chart 2).

The $\mathrm{C}_{6} \mathrm{~F}_{5}$ borane substituent may also display altered orientations within these classes, resulting in several structural forms. For borohydride $2 \mathrm{H}^{-}$, DFT calculations predict a $c_{1}$-type conformation to be the most stable form, wherein one of the $\mathrm{C}_{6} \mathrm{~F}_{5}$ rings is in stacking arrangement with the phenyl substituent of the chiral unit. ${ }^{28}$ This borohydride structure was characterized experimentally via $\mathrm{X}$-ray diffraction analysis of compound $\mathrm{PH}^{+} / 2 \mathrm{H}^{-}$, and it was assumed to play an important role in the catalytic process. ${ }^{12 b}$ In principle, both $E$ and $Z$ isomers of iminium $\mathrm{imH}^{+}$could be produced in the $\mathrm{H}_{2}$ activation step, so we have considered this possibility in our computational analysis as well.

For the $\mathrm{imH}^{+} / 2 \mathrm{H}^{-}$ion pair intermediate, we carried out an extensive conformational analysis and identified 14 different isomeric forms all lying within a $5 \mathrm{kcal} / \mathrm{mol}$ free energy range. ${ }^{29}$ A few representative structures are displayed in Figure 2.

The most stable form of $\mathrm{im} \mathrm{H}^{+} / 2 \mathrm{H}^{-}$involves a $c_{1}$ borohydride conformer with the $\mathrm{B}-\mathrm{H}$ bond interacting closely with the iminium $\mathrm{N}-\mathrm{H}$ group $\left(\mathrm{H} \cdots \mathrm{H} / c_{1}\right.$ in Figure 2). This $\mathrm{imH}^{+} / 2 \mathrm{H}^{-}$ isomer is formed directly after transition state $\mathbf{T S}_{\mathrm{HH}} \mathrm{im} / 2$, and it is predicted to be $2.0 \mathrm{kcal} / \mathrm{mol}$ above the reactant state $(\mathrm{im}+\mathbf{2}+$ $\mathrm{H}_{2}$ ). The dihydrogen bond is apparent from the very short intermolecular $\mathrm{H} \cdots \mathrm{H}$ distance $(1.53 \AA)$, and it provides considerable stabilization for the ion-pair intermediate. ${ }^{30}$ Isomer $\mathrm{H} \cdots \mathrm{H} / c_{2}$ features a dihydrogen bonding interaction as well; however, the borohydride anion adopts a $c_{2}$-type conformation. This form lies at $2.8 \mathrm{kcal} / \mathrm{mol}$ in free energy. Isomeric forms with $\mathrm{B}-\mathrm{H}$ bonds pointing toward the electrophilic carbon atom of the substrate $\left(\mathrm{H} \cdots \mathrm{C} / c_{1}\right.$ and $\mathrm{H} \cdots \mathrm{C} / c_{2}$ in Figure 2$)$ are notably less stable as compared to their $\mathrm{H} \cdots \mathrm{H} / c_{\mathrm{i}}$ analogues; however, these isomers are structurally well prepared for the HT step of the catalytic cycle. Our computational analysis indicates that the $\mathrm{H} \cdots \mathrm{H}$ and $\mathrm{H} \cdots \mathrm{C}$ type $\mathrm{imH}^{+} / 2 \mathrm{H}^{-}$isomers can easily interconvert with each other. For instance, the transformation

Chart 2. Main Borohydride Conformers as Exemplified by $2 \mathrm{H}^{-}$

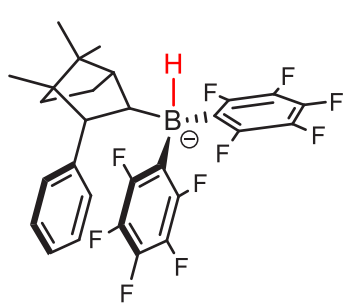

$c_{1}$

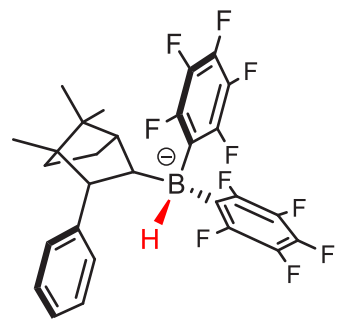

$c_{2}$

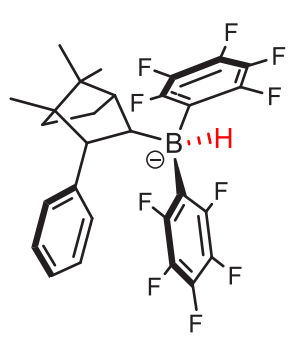

$c_{3}$ 


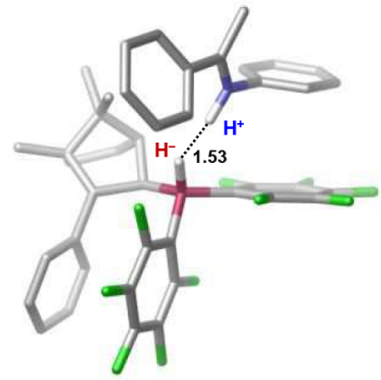

$\mathrm{H} \cdots \mathrm{H} / \mathrm{c}_{1}(2.0)$

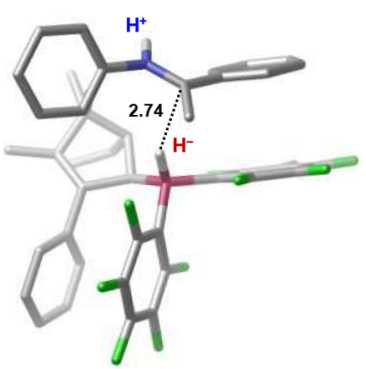

$\mathrm{H} \cdots \mathrm{C} / \mathrm{c}_{1}(6.9)$

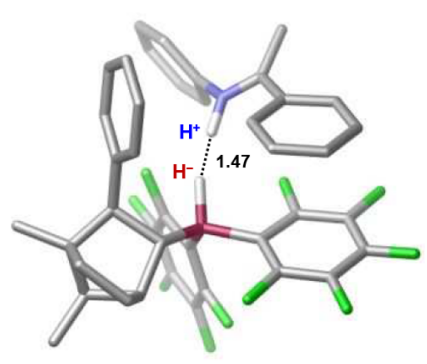

$\mathrm{H} \cdots \mathrm{H} / c_{2}(2.8)$

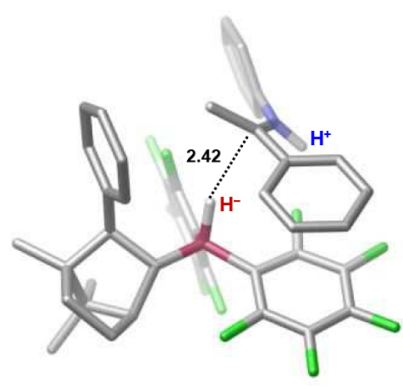

$\mathrm{H} \cdots \mathrm{C} / \mathrm{c}_{2}(7.2)$

Figure 2. Selected structures of $\mathrm{imH}^{+} / 2 \mathrm{H}^{-}$ion pair intermediates. In the labeling, $\mathrm{H} \cdots \mathrm{H}$ and $\mathrm{H} \cdots \mathrm{C}$ refer to structures with $\mathrm{B}-\mathrm{H}$ units pointing to iminium $\mathrm{N}-\mathrm{H}$ bond or to prochiral $\mathrm{C}$ atom; $c_{1}$ and $c_{2}$ denote two different borohydride conformers. Relative stabilities (in $\mathrm{kcal} / \mathrm{mol}$, with respect to the $\mathrm{im}+\mathbf{2}+\mathrm{H}_{2}$ ) are given in parentheses. Selected bond distances are in angstroms.

of isomer $\mathrm{H} \cdots \mathrm{H} / c_{2}$ to $\mathrm{H} \cdots \mathrm{C} / c_{2}$ shown in Figure 2 can take place via a barrier of only $5.3 \mathrm{kcal} / \mathrm{mol}$. Computations also suggest that facile transformation between the $c_{1}$ and $c_{2}$ borohydride conformers is feasible; the free energy barrier estimated for the $c_{1}$

$\rightarrow c_{2}$ conversion is only $8.7 \mathrm{kcal} / \mathrm{mol}^{31}$ These results imply that the array of conformational isomers identified computationally for the structurally flexible ion-pair intermediate $\mathrm{imH}^{+} / 2 \mathrm{H}^{-}$is likely in fast equilibrium even at room temperature.

Hydride Transfer Transition States for Borane 2. The conformational space of HT transition states leading to the $(R)$ am and $(S)$-am enantiomeric products were explored comprehensively, and we identified a set of energetically lowlying conformers on both pathways. The relative stabilities of the most stable structures are summarized in a free energy diagram shown in Figure 3, wherein selected transition-state structures are also depicted.

The most favored HT transition state corresponds to the formation of product $(R)$-am (see TS-2-R $\mathbf{R}_{\mathbf{1}}$ in Figure 3), and it is predicted to be $14.8 \mathrm{kcal} / \mathrm{mol}$ with respect to the reactant state $\left(\mathrm{im}+\mathbf{2}+\mathrm{H}_{2}\right)$. In this structure, the borohydride that donates $\mathrm{H}^{-}$to the iminium has a $c_{2}$ conformation, which is somewhat surprising because the $c_{2}$ form of $2 \mathrm{H}^{-}$is predicted to be $4.7 \mathrm{kcal} /$ mol less stable as compared to the $c_{1}$ form. ${ }^{28}$ Several intermolecular contacts, such as $\pi-\pi$ stacking between the iminium phenyl and the borohydride $\mathrm{C}_{6} \mathrm{~F}_{5}$ substituents, or $\mathrm{CH} \cdots \pi$ interaction between the iminium $\mathrm{CH}_{3}$ and the borohydride phenyl groups, are noticeable in $\mathbf{T S}-\mathbf{2}-\mathbf{R}_{\mathbf{1}}$. As shown previously for TM-catalyzed hydrogenation reactions, these types of noncovalent interactions can strongly influence the stereochemical outcome; ${ }^{32,33}$ therefore, they may provide notable stabilization to transition state $\mathbf{T S}-\mathbf{2}-\mathbf{R}_{\mathbf{1}}$ as well. Additional HT transition states involving the $c_{2}$ form of $2 \mathrm{H}^{-}$ could be identified on the $(R)$ reaction pathway (TS-2- $\mathbf{R}_{2}$ and TS-2-R $\mathbf{R}_{3}$ ), but they are computed to be $2-3 \mathrm{kcal} / \mathrm{mol}$ less stable than TS-2-R $\mathbf{R}_{\mathbf{1}}$. The extent of noncovalent interactions in higher lying transition states is reduced, which corroborates the stabilizing nature of these intermolecular contacts.

Interestingly, the most favored transition state comprising a $c_{1}$-type $2 \mathrm{H}^{-}$conformation $\left(\mathbf{T S}-\mathbf{2}-\mathbf{R}_{4}\right)$ is predicted to be even
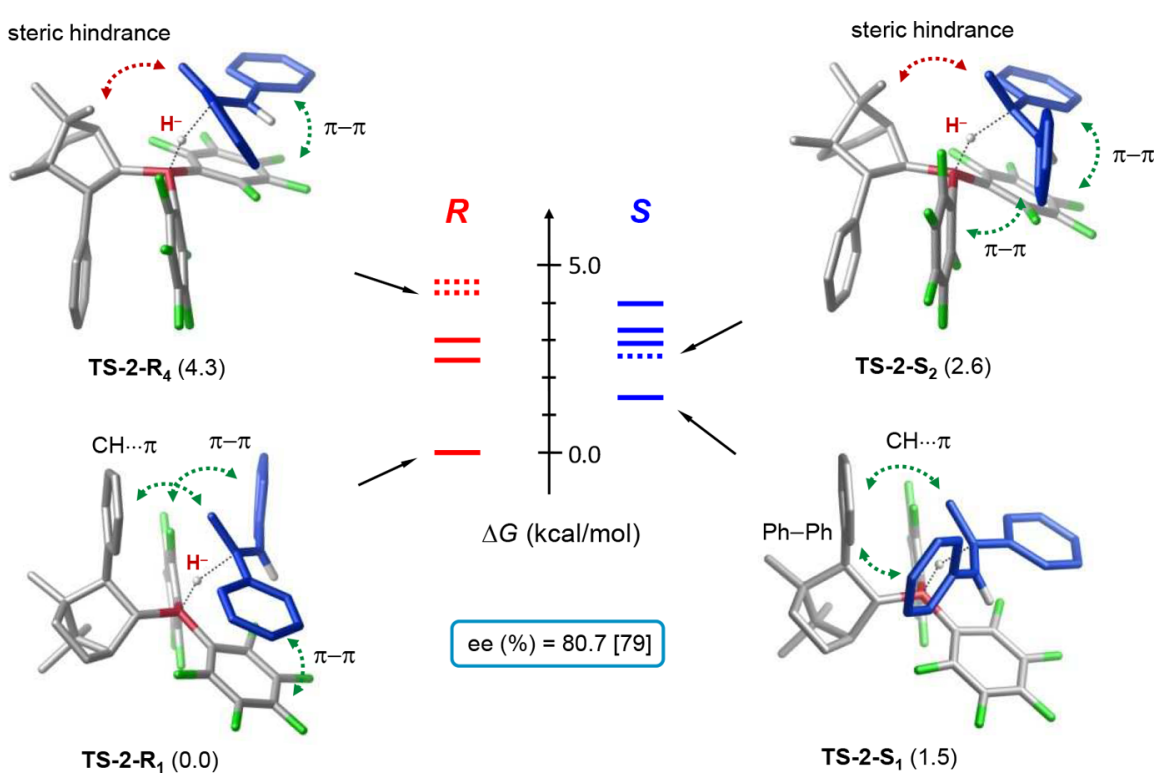

Figure 3. Hydride transfer transition states identified computationally for hydrogenation of im with borane 2. Each line on the free energy diagram represents a specific isomeric form with the computed relative stability. TS-2- $\mathbf{R}_{\mathbf{i}}$ and $\mathbf{T S}-\mathbf{2}-\mathbf{S}_{\mathbf{i}}$ denote transition states leading to $(R)$-am and $(S)$-am products (index $i$ defines the stability order). Full and dotted lines refer to transition state isomers involving $c_{2}$ and $c_{1}$ borohydride conformers. Selected structures are depicted and marked with arrows; their relative stabilities are given in parentheses (in $\mathrm{kcal} / \mathrm{mol}$, with respect to the most stable form). The iminium component is highlighted in blue for clarity. Green and red dotted arrows indicate attractive and repulsive intermolecular contacts. Computed and experimental (in brackets) ee data are shown below the diagram. 


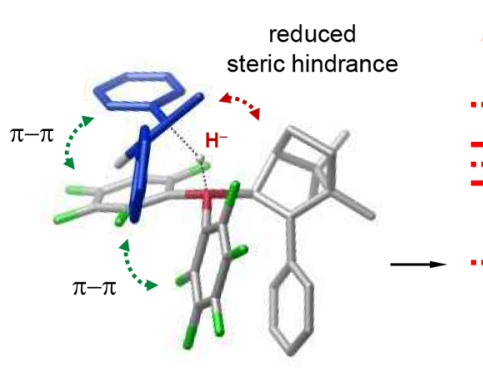

TS-3- $\mathbf{R}_{\mathbf{1}}(0.4)$

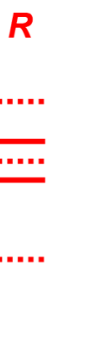

$\Delta G(\mathrm{kcal} / \mathrm{mol})$

ee $[\%]=33.7$ [48]
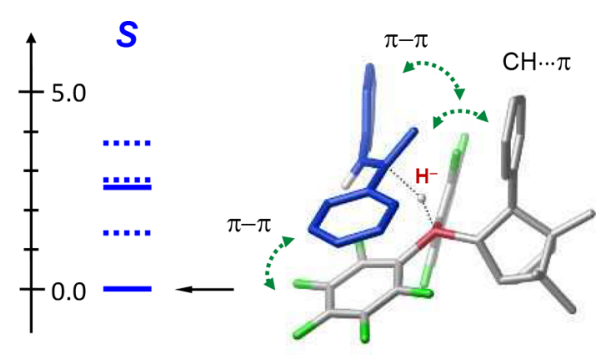

TS-3-S 1 (0.0)

Figure 4. Hydride transfer transition states identified computationally for hydrogenation of im with borane 3 . For further relevant information, see the caption of Figure 3.

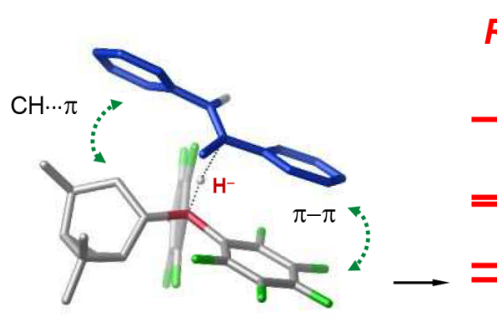

TS-1- $R_{1}(0.0)$

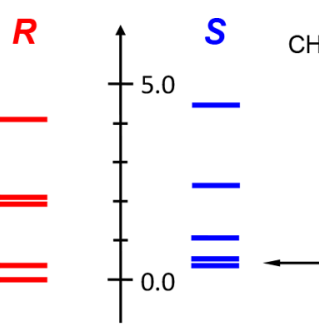

$\Delta G(\mathrm{kcal} / \mathrm{mol})$

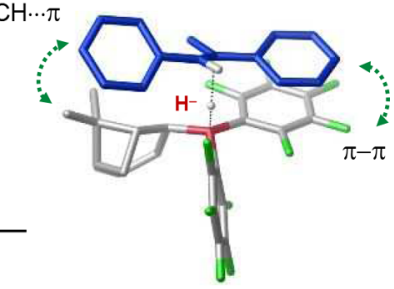

TS-1-S 1 (0.4)

ee $[\%]=1.5[13]$

Figure 5. Hydride transfer transition states identified computationally for hydrogenation of im with borane 1. For further relevant information, see the caption of Figure 3. The classification of transition states according to the borohydride conformations is not relevant in this case. The lowest lying energy level in the $(S)$ ensemble (at $0.4 \mathrm{kcal} / \mathrm{mol}$ ) represents two different structures, TS-1-S $\mathbf{1}$ and TS-1-S $\mathbf{S}_{\mathbf{2}}$, of which only the former is depicted.

higher in free energy (at $4.3 \mathrm{kcal} / \mathrm{mol}$ ). This structure is destabilized by steric repulsion between the chiral borane substituent and the methyl group of iminium $\mathrm{imH}^{+}$, which becomes too close as demonstrated by rather short $\mathrm{H} \cdots \mathrm{H}$ distances measured in the optimized structure $(\sim 2.1 \AA) .{ }^{34}$

On the HT reaction pathway that furnishes the minor $(S)$-am enantiomeric product, iminium im $\mathrm{H}^{+}$approaches $2 \mathrm{H}^{-}$with the other face. The most stable transition state TS-2-S $\mathbf{S}_{\mathbf{1}}$ also involves a $c_{2}$-type borohydride; however, the intermolecular contacts are different from those in TS-2-R $\mathbf{R}_{\mathbf{1}}$. Although the $\mathrm{CH} \cdots \pi$ interaction between the iminium $\mathrm{CH}_{3}$ and the borohydride phenyl groups is still present in TS-2-S $\boldsymbol{S}_{1}$, no close $\pi-\pi$ stacking interactions are perceived. The phenyl substituent of the borohydride interacts with the iminium phenyl group, but this aryl-aryl interaction is far from the ideal stacking or T-shaped arrangements. Overall, transition state TS-2-S $S_{1}$ is found to be 1.5 $\mathrm{kcal} / \mathrm{mol}$ less stable than $\mathbf{T S}-\mathbf{2}-\mathbf{R}_{\mathbf{1}}$. Several other close-lying transition states were located on the $(S)$ pathway, of which the next in the stability order (TS-2-S $\left.S_{2}\right)$ incorporates a $c_{1}$-type borohydride. Steric hindrance is also a characteristic feature of this transition state structure (similarly to TS-2-R $\mathbf{R}_{\mathbf{4}}$ ), but due to more favorable $\pi-\pi$ stacking interactions, TS-2-S is more stable than TS-2-R .

The enantioselectivity of catalytic imine hydrogenation is under kinetic control. ${ }^{35}$ The rapid equilibration of various isomers of the $\mathrm{imH}^{+} / 2 \mathrm{H}^{-}$intermediate enables the application of the Curtin-Hammett principle, so the enantiomeric excess (ee) can be estimated from the Boltzmann-weighted relative Gibbs free energies of the identified HT transition states. Using this procedure, the ee of the kinetically favored $(R)$-am product in the present reaction is computed to be $80.7 \%$, which is in good agreement with the experimental observation (79\%). ${ }^{12 b, 36}$

Reaction with Borane 3. Assuming that the concepts discussed in the previous sections and our conclusions regarding the hydrogenation mechanism can be extended to the analogous reactions with other boranes, we carried out a systematic computational study for the HT process with borane 3 as well. Borane $\mathbf{3}$ is the diastereomeric pair of $\mathbf{2}$ having the same bridged bicyclic $(R)$-camphor derived framework with the altered stereochemical arrangement of the $\mathrm{B}\left(\mathrm{C}_{6} \mathrm{~F}_{5}\right)_{2}$ and $\mathrm{Ph}$ units (see Chart 1). The free energy diagram illustrating the relative stabilities of HT transition states computed for im hydrogenation with borane 3 is shown in Figure 4 along with the most stable structures identified on the $(R)$ and $(S)$ pathways.

The most favored transition state $\mathbf{T S}-\mathbf{3}-\mathrm{S}_{\mathbf{1}}$ can be regarded as a pseudoenantiomeric form of TS-2-R $\mathbf{R}_{1}$ displaying a $c_{2}$-type borohydride conformation and the same type of stabilizing intermolecular contacts $\left(\pi-\pi\right.$ stacking and $\mathrm{CH}_{3}-\pi$ interactions). In this reaction, however, HT transition states involving the $c_{1}$ borohydride conformation tend to be energetically more favored as compared to those in the reaction with borane $\mathbf{2}$, and in fact, the lowest lying transition state on the minor $(R)$ pathway (TS-3-R $\mathbf{R}_{1}$ ) encompasses a $c_{1}$-type borohydride. This latter transition state is computed to be only $0.4 \mathrm{kcal} / \mathrm{mol}$ apart from TS-3-S . Our structural analysis points to a somewhat reduced steric hindrance between the methyl group of iminium $\mathrm{imH}^{+}$and the chiral bicyclic $3 \mathrm{H}^{-}$substituent in transition states with $c_{1}$ borohydrides, which explains the tendency of having these transition state structures more populated in the reaction with borane $3 .{ }^{37}$ As a result of reduced steric repulsion, two

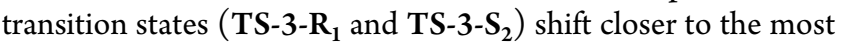


favored TS-3-S $S_{1}$ structure in free energy, which of course influences the enantioselectivity as well. Computations predict ee $=33.7 \%$ for this reaction, which is consistent with the measured enantioselectivity (48\%). ${ }^{12 b}$

Reaction with Borane 1. HT transition state isomers for the reaction with borane $\mathbf{1}$ were also explored, and we identified a set of structures, some of which were found to have very similar relative stabilities (see Figure 5). ${ }^{38}$

Due to the lack of any bulky substituent on the $\alpha$-pinene framework in borane $\mathbf{1}$ (such as $\mathrm{Ph}$ in $\mathbf{2}$ and 3), the chiral environment around the reactive $\mathrm{B}-\mathrm{H}$ bond of borohydride $1 \mathrm{H}^{-}$is less defined. For instance, no multiple combinations of stabilizing $\pi-\pi$ stacking and $\mathrm{CH}_{3}-\pi$ contacts are developed between $1 \mathrm{H}^{-}$and $\mathrm{imH}^{+}$; therefore, no structure with particularly enhanced stabilities exists. For the same reason, the most favored transition states on the competing $(R)$ and $(S)$ pathways become less separated in free energy. Indeed, calculations predict five different transition state structures within a $0.5 \mathrm{kcal} / \mathrm{mol}$ range, and the most stable diastereomeric forms (TS-1-R $\mathbf{R}_{\mathbf{1}}$ and TS-1-S $\mathbf{S}_{\mathbf{1}}$ ) display very similar intermolecular contacts (a single $\pi-\pi$ stacking and a $\mathrm{CH} \cdots \pi$ type interaction; see Figure 5). Consequently, a very low enantioselectivity is predicted (ee $=1.5 \%$ ), which is again in line with experimental observations $(13 \%) .{ }^{12 a}$

On the Origin of Stereoselectivity. Several important findings that emerged from our computational analysis are worth highlighting when discussing the origin of enantioselectivity in the examined reactions. First, it appears that for camphor-derived boranes $\mathbf{2}$ and $\mathbf{3}$, the stereoselectivity of imine hydrogenation is dictated by thermodynamically less favored borohydride conformers of $c_{2}$-type and not by the most stable $c_{1}$ form that is observed experimentally. The $c_{2}$ conformer of $2 \mathrm{H}^{-}$is clearly more reactive in hydride transfer to $\mathrm{imH}^{+}$and with its phenyl substituent arranged next to the $\mathrm{B}-\mathrm{H}$ bond provides a chiral binding site for the approaching protonated substrate. The chiral environment is defined by the three aromatic rings of the borohydride resulting in facial selectivity for the hydride transfer (Figure 6).

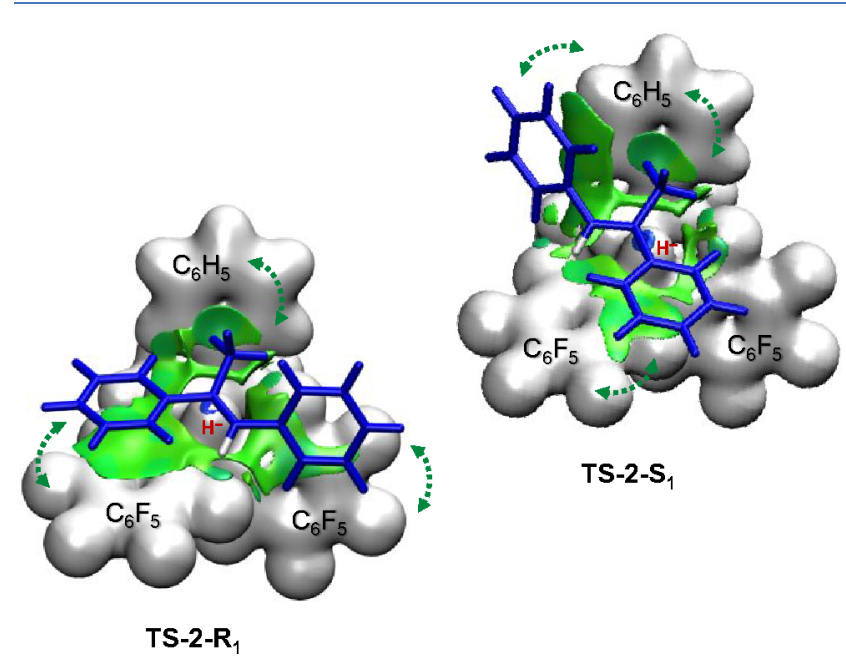

Figure 6. Noncovalent interactions (NCI) in hydride transfer transition states TS-2- $\mathbf{R}_{1}$ and TS-2-S. The borohydride is represented by a gray isodensity surface $(\rho=0.01 \mathrm{au})$; the iminium is shown in blue. The applied cutoff for reduced density gradient is $s=0.3 \mathrm{au} . \pi-\pi$ stacking and $\mathrm{CH}_{3}-\pi$ interactions are highlighted by green dotted arrows.
The stereoinduction in the present reactions is found to be influenced by multiple stabilizing noncovalent interactions between $2 \mathrm{H}^{-}$and $\mathrm{imH}^{+}$, which are apparent from the NCI plots ${ }^{39}$ generated for transition states TS-2-R $\mathbf{R}_{\mathbf{1}}$ and TS-2-S $\mathbf{1}$. The green surface areas on these plots represent weak attractive noncovalent interactions corresponding to $\pi-\pi$ stacking, $\mathrm{CH}_{3}-\pi, \mathrm{Ph}-\mathrm{Ph}$, etc. intermolecular contacts. As noted above, and also illustrated in Figure 6, the higher stability of transition state $\mathbf{T S}-\mathbf{2}-\mathbf{R}_{\mathbf{1}}$ could be associated with more favorable aromatic $\left(\mathrm{C}_{6} \mathrm{~F}_{5} \cdots \mathrm{C}_{6} \mathrm{H}_{5}\right)$ interactions in this structure as compared to that in TS-2-S .

Proposed Modifications in Borane 2. Our computational analysis indicates that the phenyl substituent of camphor derived boranes is an important stereocontrol element in catalytic hydrogenation of im. This is further supported by calculations carried out for a model reaction catalyzed by a borane derived from 2 by omitting the $\mathrm{Ph}$ substituent. These calculations predict very low ee (only 5.6\%) in this case. ${ }^{40}$ We envisioned that additional substitutions implemented on the $\mathrm{Ph}$ group of borane 2 , or replacing the $\mathrm{Ph}$ group by a larger aromatic ring, could alter the enantioselectivity of hydrogenation. The boranes considered for additional computational analysis are shown in Figure $7 .^{41}$

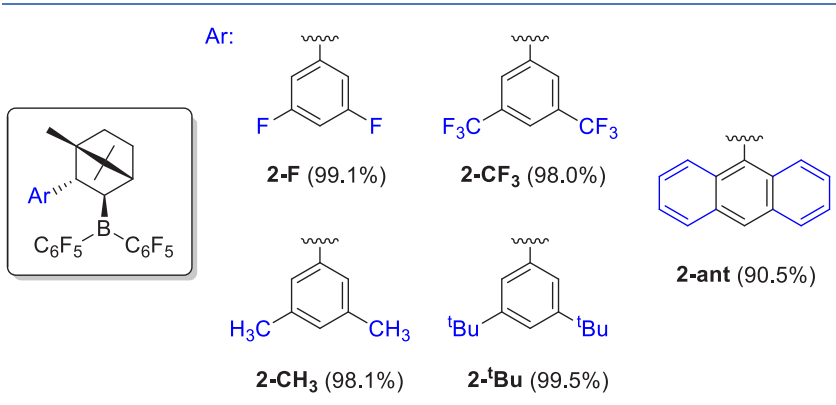

Figure 7. Modified boranes and predicted ee data.

DFT calculations carried out for reactions catalyzed by boranes derived from 2 by adding either electron-withdrawing ( $\mathrm{F}$ and $\left.\mathrm{CF}_{3}\right)$ or electron-donating $\left(\mathrm{CH}_{3}\right.$ and $\left.{ }^{\mathrm{t}} \mathrm{Bu}\right)$ groups at the meta positions of the $\mathrm{Ph}$ ring predicted significantly enhanced enantioselectivities (ee's above 98\%). We find that in these reactions, HT transition state conformers analogous to TS-2-S are notably destabilized with respect to the corresponding $\mathbf{R}_{\mathbf{1}}$ structures. This is due to steric effects induced by the meta substituents on the catalyst $\mathrm{Ph}$ group. As discussed above, transition state $\mathbf{T S}-2-S_{1}$ is displaced only by $1.5 \mathrm{kcal} / \mathrm{mol}$ from the most stable TS-2-R $\mathbf{R}_{\mathbf{1}}$ structure (Figure 3), but this free energy difference increases to $4-5 \mathrm{kcal} / \mathrm{mol}$ with the modified boranes. The strength of the $\mathrm{CH}_{3}-\pi$ interaction is also altered by introducing the meta substituents, ${ }^{42}$ but these interactions are equally present in the most stable diastereomeric transition states $\left(\mathbf{R}_{1}\right.$ and $S_{1}$; see Figure 6$)$, so they have no considerable influence on the enantioselectivity. For borane 2-ant, calculations predict somewhat lower ee $(90.5 \%)$. In this borane variant, the $c_{1}$-type borohydride conformations attain further stabilization via the extended aromatic stacking interactions, so all HT transition states of $c_{1}$-type shift closer in free energy to the most stable form, reducing the enantioselectivity.

Experiments with Borane 2-F. To assess the reliability of DFT predictions, we first synthesized borane 2-F according to the procedure established for the reported camphor-derived boranes 2 and $3^{12}$ (Scheme 3 ). Reaction of enantiopure ( $1 R$ )- 
Scheme 3. Synthesis of Chiral Borane 2-F

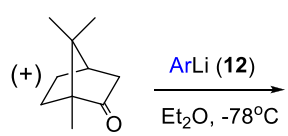

11

Ar: $3,5-\mathrm{F}_{2}-\mathrm{C}_{6} \mathrm{H}_{3}$

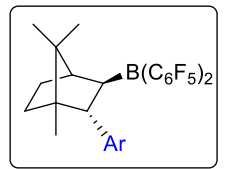

2-F, $52 \%$

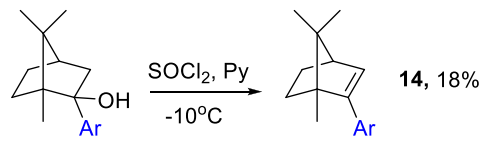

13 recrystallization

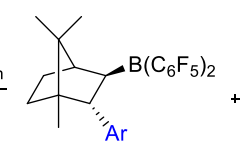

$2-\mathbf{F}$

$$
7: 1
$$

attempt to provide a plausible explanation, we decided to assess the stability of 2-F upon the hydrogenation process. In a thickwall gas-tight NMR tube, a stoichiometric mixture of 2-F and im in deuterated toluene was pressurized with 10 bar of dihydrogen. After $1 \mathrm{~h}$, the sample was analyzed by ${ }^{1} \mathrm{H} \mathrm{NMR}$, which revealed appearance of a new set of signals related to camphor scaffold in addition to those of 2-F ( $44 \%$ conversion). Although we could not reliably identify the structure of the newly formed species, a detailed NMR data analysis $\left({ }^{19} \mathrm{~F},{ }^{11} \mathrm{~B}, \mathrm{HH}\right.$ COSY and $\mathrm{HH}$ NOESY, see the SI) suggested that it was isomeric to both 2-F and $2-\mathbf{F}^{\prime}$. The same species, albeit to a lesser extent (with $18 \%$ conversion), was formed when am was probed instead of im under the same reaction condition. On the basis of these observations, it is reasonable to assume that the new borane species produced in the catalytic process may catalyze a parallel low-enantioselective hydrogenation of im, which deteriorates the overall enantioselectivity of this reaction.

Experiments with Borane 2- ${ }^{\mathrm{B}} \mathrm{Bu}$. Next, we decided to synthesize and to test borane $2-{ }^{\mathrm{t}} \mathbf{B u}$, which involves bulkier 3,5substituents on the phenyl group. Attempt to produce $2-{ }^{t} \mathbf{B u}$ following the established procedure as for 2-F was unsuccessful due to predominant enolization of $\mathbf{1 1}$ upon addition of either 3,5-di-tert-butylphenyllithium or -magnesium bromide. Therefore, we designed an alternative synthetic route outlined in Scheme 4. Camphor 11 was transformed into bromobornene 17

Scheme 4. Synthesis of Chiral Borane $2-{ }^{t} \mathrm{Bu}$

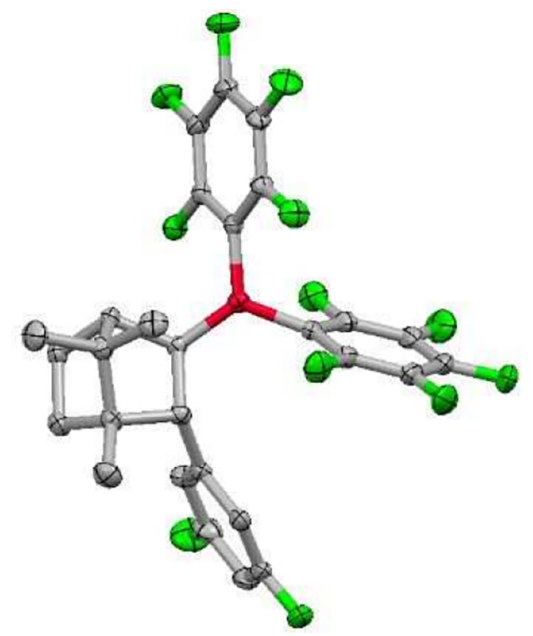

Figure 8. Crystal structure of borane 2-F. $\mathrm{H}$ atoms are omitted for clarity.

Catalytic hydrogenation of imine im with $2-F$ gave high conversions (above 90\%) in $1 \mathrm{~h}$ at room temperature, however, no improvement could be obtained for the enantioselectivity as compared to that observed by Klankermayer et al.; the ee measured in our experiments reached $75 \%$ at most, depending on the reaction conditions (see Table S6 in the Supporting Information). Noteworthy, hydrogenation of im in the presence of external base 1,2,2,6,6-pentamethylpiperidine (PMP, $5 \mathrm{~mol}$ $\%)$ gave only $13 \%$ conversion. These results support the view emerging from the computational analysis that catalytic hydrogenation takes place via cycle 2 (Scheme 2) even in the presence of an external base.

The reason for the disagreement we see between the computed and measured enantioselectivities is not fully settled. The discrepancy may certainly arise from the inaccuracy of the DFT calculations, although the good match obtained for boranes 1-3 points to other, yet unknown, factors. In an

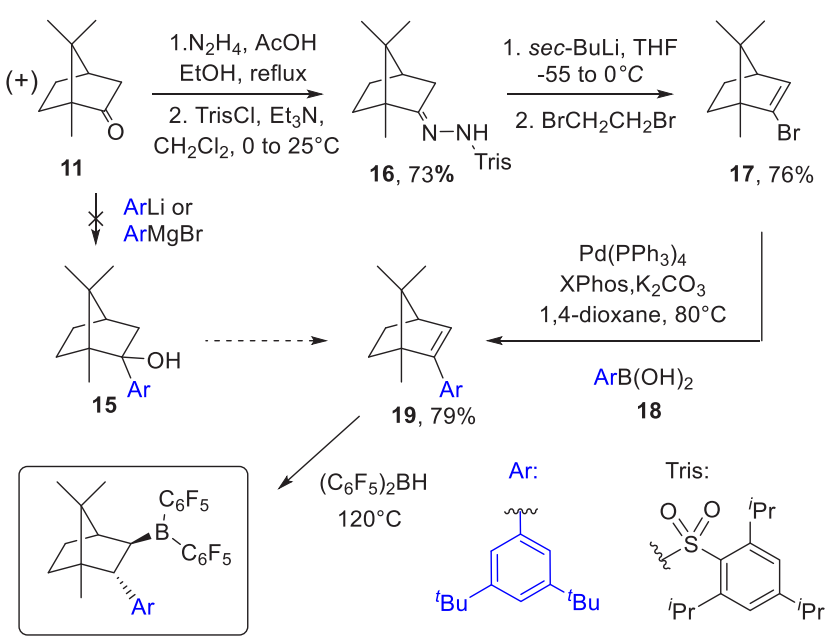

2-'Bu, 99\% NMR yield

$83 \%$ after recrystallization

via the Shapiro reaction. The subsequent Suzuki-Miyaura crosscoupling of 17 with 3,5-di-tert-butylphenyl boronic acid 18 gave alkene 19 in $79 \%$ yield. The hydroboration of 19 using Piers' borane under solvent-free conditions gave exclusively diastereomer $\mathbf{2}^{\mathrm{t}} \mathbf{\mathrm { Bu }}$ in nearly quantitative yield. Recrystallization of 2 - ${ }^{\mathrm{t}} \mathrm{Bu}$ from $n$-pentane at $-20^{\circ} \mathrm{C}$ provided colorless crystals $(83 \%$ yield) suitable for X-ray crystallographic analysis (Figure 9).

Hydrogenation of imine im using $5 \mathrm{~mol} \%$ borane $2{ }^{-{ }^{t}} \mathbf{B u}$ at room temperature and 50 bar $\mathrm{H}_{2}$ in toluene gave only moderate conversion (52\%) after $1 \mathrm{~h}$, however, the enantioselectivity was high (91\% ee; see Table S7 in the Supporting Information). Prolongation of reaction time to $24 \mathrm{~h}$ led to quantitative hydrogenation of im with similarly high enantiomeric excess (92\%), demonstrating the stability of the catalyst under the applied conditions. Solvent screening showed only a small effect on the stereoselectivity, giving slightly lower ees in etherial 


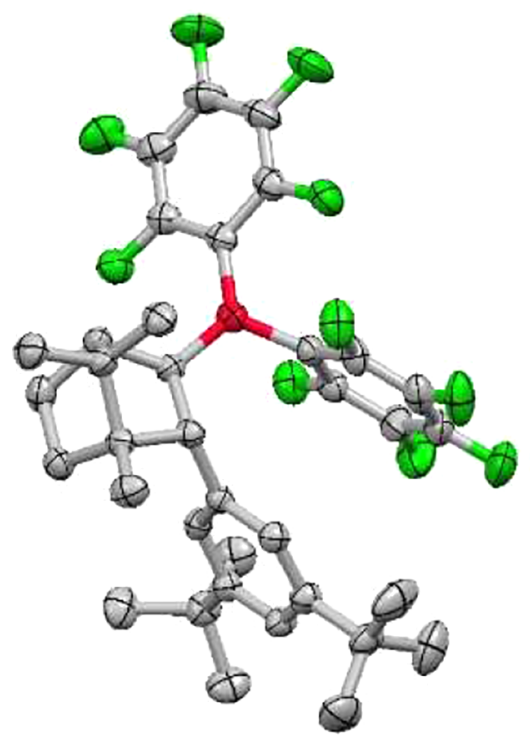

Figure 9. Crystal structure of borane $2{ }^{\mathrm{t}} \mathrm{Bu}$. $\mathrm{H}$ atoms are omitted for clarity.

solvents (see Table S7 in the Supporting Information). We note that this level of selectivity in FLP-type imine hydrogenation could only be accomplished by recently developed bicyclic borane 8 at significantly lower temperature $\left(-40{ }^{\circ} \mathrm{C}\right)$.

Broadening of substrate scope was not an objective of our present work, but catalyst $2-{ }^{t} \mathbf{B u}$ was tested for the hydrogenation of a few additional imines as well (Table 1 and also Table S8 in the Supporting Information). Various $N$-arylsubstituted-imines 20a-20d and imine 20e bearing non-

Table 1. Asymmetric Hydrogenations of Imines with $2-^{\mathrm{t}} \mathrm{Bu}{ }^{a}$

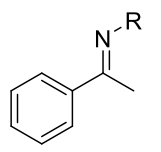

im, 20a-20g

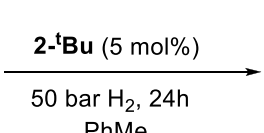

$\mathrm{PhMe}$
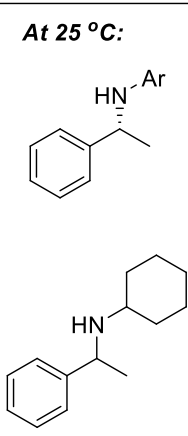

$21 \mathbf{e}$

$99 \%, 93 \%$ ee $(n d)$

At $-15^{\circ} \mathrm{C}$

$99 \%, 95 \%$ ee $(S)$

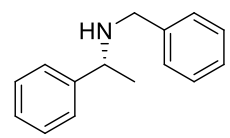

$21 f$

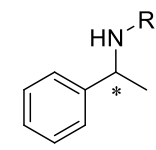

am, 21a-21g$$
\text { At }-15^{\circ} \mathrm{C}:
$$

$99 \%, 33 \%$ ee $(R)$

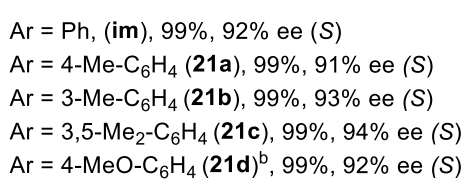

(S)

${ }^{a}$ Substrate $(0.25 \mathrm{mmol}), \mathrm{PhMe}(0.5 \mathrm{ml})$, conversion by ${ }^{1} \mathrm{H}$ NMR spectroscopy, ee by HPLC (Chiralcel OD-H or OJ-H column). ${ }^{b}$ For detailed optimization, see Table S7 in the Supporting Information. ${ }^{c}$ Reaction time 48 h. ${ }^{d} 10 \mathrm{~mol} \%$ of 2 - ${ }^{\mathrm{B}} \mathrm{Bu}$. aromatic cyclohexyl substituent at nitrogen could be reduced with high stereoselectivities (91-94\% ee). On the other hand, hydrogenation of the benzyl-substituted imine $20 \mathrm{f}$ resulted in a dramatically lower enantioselectivity (33\%). Quantitative hydrogenation of 2-phenyl quinoline $20 \mathrm{~g}$ to 2-phenyl-1,2,3,4tetrahydroquinoline $21 \mathrm{~g}$ could also be achieved, albeit in $48 \mathrm{~h}$ with doubling of catalyst loading, and with a significantly reduced ee $(21 \%)$. Hydrogenation of selected substrates im and 20c at lower temperature $\left(-15^{\circ} \mathrm{C}\right)$ afforded slightly enhanced enantioseletivities: $95 \%$ and $96 \%$ ee, respectively.

These results highlight and confirm the importance of specific aryl-aryl and aryl-alkyl catalyst-substrate interactions in stereoinduction. For the particular borane catalyst $2-{ }^{\mathbf{t}} \mathbf{B u}$ and imines with topology analogous to im $(\mathbf{2 0 a}-\mathbf{2 0 e})$ the overall effect of attractive noncovalent and destabilizing steric interactions is highly beneficial; however, this balance is far from optimal for other substrates (20f and $\mathbf{2 0 g}$ ).

\section{SUMMARY AND CONCLUSIONS}

Utilization of chiral FLP catalysts in direct asymmetric hydrogenation of unsaturated compounds is a potential metalfree strategy in stereoselective synthesis. Remarkable developments have been achieved along this line over the past decade; however, the current level of comprehension concerning the stereoselectivity governing factors in these catalytic processes is not sufficient thus far to facilitate new catalyst design. In our present work, we performed a detailed computational analysis for imine hydrogenation reactions reported previously by the Klankermayer group, namely those catalyzed by chiral boranes derived from $(+)-\alpha$-pinene (borane $\mathbf{1}$ in Chart 1 ) and (1R)(+)-camphor (boranes 2 and 3). Although only a single imine substrate (im) was considered in our computational study, and the selection of borane catalysts is limited as well, yet several interesting findings and conclusions have emerged from our analysis, which considerably improve our understanding.

Computations carried out for imine hydrogenation with borane $\mathbf{2}$ (the most selective reaction in the series) revealed that catalysis operates preferably via $\mathrm{H}_{2}$ activation with the im/2 pair even if the borane is introduced in a phosphonium-borohydride form, as in the original experiments. This computational insight could be supported experimentally in our work. The analysis focusing on the hydride transfer step pointed to fast equilibration of various isomers of the $\mathrm{imH}^{+} / 2 \mathrm{H}^{-}$intermediate. We showed that the stereoselectivity is dictated by a thermodynamically unfavored borohydride isomer, and not by the most stable, experimentally observed form. This latter $2 \mathrm{H}^{-}$ isomer is less reactive for steric reasons. In the active form of $2 \mathrm{H}^{-}$, the phenyl substituent of the camphor framework, along with the two $\mathrm{C}_{6} \mathrm{~F}_{5}$ aromatic rings, define a chiral pocket for the approaching protonated substrate $\left(\mathrm{imH}^{+}\right)$. The most stable hydride transfer transition states are found to be stabilized by specific noncovalent interactions, such as $\pi-\pi$ stacking, $\mathrm{CH}_{3}-\pi$, and $\mathrm{Ph}-\mathrm{Ph}$ intermolecular contacts. The enantioselectivity predicted by DFT calculations is in close agreement with experimental observations, and we find similarly good match between computed and measured ee data for the reactions with boranes 1 and 3 .

Based on these promising results, we anticipated that alteration of the $\mathrm{Ph}$ substituent in borane 2 could be beneficial for stereoinduction, and indeed, calculations for boranes with 3,5-disubstituted $\mathrm{Ph}$ groups predicted significantly improved enantioselectivities. Two of these new borane candidates were selected for experimental studies. Boranes 2-F and 2- ${ }^{\mathrm{t}} \mathbf{B u}$ were 
synthesized and probed as catalysts in imine hydrogenation. No improvement in the measured ee could be demonstrated with borane 2-F, but the experiments inferred that catalytic hydrogenation could be performed at room temperature in the absence of an external base. Borane 2- ${ }^{\mathrm{t}} \mathrm{Bu}$, however, was shown to be a robust and efficient FLP catalyst in imine hydrogenation, providing ee's above $90 \%$, which could only be achieved so far at significantly lower temperature.

\section{ASSOCIATED CONTENT}

\section{SI Supporting Information}

The Supporting Information is available free of charge at https://pubs.acs.org/doi/10.1021/acscatal.0c04263.

Details regarding the computational analysis, total energies and Cartesian coordinates for the considered stationary points, and experimental details (PDF)

\section{AUTHOR INFORMATION}

\section{Corresponding Authors}

Imre Pápai - Institute of Organic Chemistry, Research Centre for Natural Sciences, H-1117 Budapest, Hungary; ○ orcid.org/0000-0002-4978-0365; Email: papai.imre@ ttk.hu

Timo Repo - Department of Chemistry, University of Helsinki, 00014 Helsinki, Finland; 10 orcid.org/0000-0002-31166199; Email: timo.repo@helsinki.fi

\section{Authors}

Andrea Hamza - Institute of Organic Chemistry, Research Centre for Natural Sciences, H-1117 Budapest, Hungary; (ㄱ) orcid.org/0000-0002-9614-8522

Kristina Sorochkina - Department of Chemistry, University of Helsinki, 00014 Helsinki, Finland

Bianka Kótai - Institute of Organic Chemistry, Research Centre for Natural Sciences, H-1117 Budapest, Hungary

Konstantin Chernichenko - Department of Chemistry, University of Helsinki, 00014 Helsinki, Finland; 이이.org/ 0000-0002-6425-5075

Dénes Berta - Institute of Organic Chemistry, Research Centre for Natural Sciences, H-1117 Budapest, Hungary;

(ㄱ) orcid.org/0000-0002-8299-3784

Michael Bolte - Institute of Inorganic Chemistry, GoetheUniversity, D-60438 Frankfurt am Main, Germany; (-) orcid.org/0000-0001-5296-6251

Martin Nieger - Department of Chemistry, University of Helsinki, 00014 Helsinki, Finland; 이이. orcid.o000-00031677-0109

Complete contact information is available at: https://pubs.acs.org/10.1021/acscatal.0c04263

\section{Author Contributions}

${ }^{\S}$ A.H. and K.S. contributed equally.

\section{Notes}

The authors declare no competing financial interest. CCDC 2007899 (2-F), and $2007900\left(2-^{t} \mathbf{B u}\right)$ contain the supplementary crystallographic data for this paper. These data can be obtained free of charge from The Cambridge Crystallographic Data Centre via www.ccdc.cam.ac.uk/data_request/.

\section{ACKNOWLEDGMENTS}

Financial support for this work was provided by the Hungarian Scientific Research Fund Grant No. K-115660) and from the
Academy of Finland (Grant No. 316207). A.H. acknowledges the Janos Bolyai Scholarship from Hungarian Academy of Sciences. Computer facilities provided by NIIF HPC Hungary (project 85708 kataproc) are also acknowledged. We are grateful to Dr. Tibor András Rokob for insightful discussions and to Dr. Péter Nagy for assisting with benchmark studies.

\section{REFERENCES}

(1) (a) Nugent, T. C. Chiral Amine Synthesis: Methods, Developments and Applications; Wiley-VCH: Weinheim, 2010. (b) Nugent, T. C.; ElShazly, M. Chiral Amine Synthesis - Recent Developments and Trends for Enamide Reduction, Reductive Amination, and Imine Reduction. Adv. Synth. Catal. 2010, 352, 753-819.

(2) For selected reviews, see: (a) Spindler, F.; Blaser, H.-U. Enantioselective Hydrogenation of $\mathrm{C}=\mathrm{N}$ Functions and Enamines. In Handbook of Homogenous Hydrogenation; de Vries, J. G., Elsevier, C. J., Eds.; Wiley-VCH: Weinheim, 2007; Vol. 3, pp 1193-1214. (b) Xie, J. H.; Zhu, S. F.; Zhou, Q. L. Transition Metal-Catalyzed Enantioselective Hydrogenation of Enamines and Imines. Chem. Rev. 2011, 111, 17131760. (c) Yu, Z.; Jin, W.; Jiang, Q. Brønsted Acid Activation Strategy in Transition-Metal Catalyzed Asymmetric Hydrogenation of $\mathrm{N}$ Unprotected Imines, Enamines, and N-Heteroaromatic Compounds. Angew. Chem., Int. Ed. 2012, 51, 6060-6072. (d) Xie, J.-H.; Zhu, S.-F.; Zhou, Q.-L. Recent Advances in Transition Metal-Catalyzed Enantioselective Hydrogenation of Unprotected Enamines. Chem. Soc. Rev. 2012, 41, 4126. (e) Stereoselective Formation of Amines; Li, W., Zhang, X., Eds.; Springer-Verlag: New York, 2014; Vol. 343. (f) Liu, Y.; Yue, X.; Luo, C.; Zhang, L.; Lei, M. Mechanisms of Ketone/Imine Hydrogenation Catalyzed by Transition-Metal Complexes. Energy Environ. Mater. 2019, 2, 292-312.

(3) For related reviews, see: (a) Hopmann, K. H.; Bayer, A. Enantioselective Imine Hydrogenation with Iridium-Catalysts: Reactions, Mechanisms and Stereocontrol. Coord. Chem. Rev. 2014, 268, 59-82. (b) Mwansa, J. M.; Page, M. I. Catalysis, Kinetics and Mechanisms of Organo-Iridium Enantioselective HydrogenationReduction. Catal. Sci. Technol. 2020, 10, 590-612. (c) Cui, C.-X.; Chen, H.; Li, S.-J.; Zhang, T.; Qu, L.-B.; Lan, Y. Mechanism of IrCatalyzed Hydrogenation: A Theoretical View. Coord. Chem. Rev. 2020, 412, 213251.

(4) For a review on metal-free hydrogenation strategies, see: Rossi, S.; Benaglia, M.; Massolo, E.; Raimondi, L. Organocatalytic Strategies for Enantioselective Metal-Free Reductions. Catal. Sci. Technol. 2014, 4, $2708-2723$.

(5) For a review on organocatalytic transfer hydrogenation and hydrosilation reactions, see: Herrera, R. P. Organocatalytic Transfer Hydrogenation and Hydrosilylation Reactions. Top. Curr. Chem. 2016, 374, 29.

(6) Welch, G. C.; Juan, R. R. S.; Masuda, J. D.; Stephan, D. W. Reversible, Metal-Free Hydrogen Activation. Science 2006, 314, 11241126.

(7) For the first influential works, see: (a) Chase, P. A.; Welch, G. C.; Jurca, T.; Stephan, D. W. Metal-Free Catalytic Hydrogenation. Angew. Chem., Int. Ed. 2007, 46, 8050-8053. (b) Chase, P. A.; Jurca, T.; Stephan, D. W. Lewis Acid-Catalyzed Hydrogenation: $B\left(\mathrm{C}_{6} \mathrm{~F}_{5}\right)_{3}-$ Mediated Reduction of Imines and Nitriles with $\mathrm{H}_{2}$. Chem. Commun. 2008, 14, 1701. (c) Wang, H.; Fröhlich, R.; Kehr, G.; Erker, G. Heterolytic Dihydrogen Activation with the 1,8-Bis(Diphenylphosphino)Naphthalene $/ \mathrm{B}\left(\mathrm{C}_{6} \mathrm{~F}_{5}\right)_{3}$ Pair and Its Application for Metal-Free Catalytic Hydrogenation of Silyl Enol Ethers. Chem. Commun. 2008, 45, 5966. (d) Spies, P.; Schwendemann, S.; Lange, S.; Kehr, G.; Fröhlich, R.; Erker, G. Metal-Free Catalytic Hydrogenation of Enamines, Imines, and Conjugated Phosphinoalkenylboranes. Angew. Chem., Int. Ed. 2008, 47, 7543-7546. (e) Sumerin, V.; Schulz, F.; Atsumi, M.; Wang, C.; Nieger, M.; Leskelä, M.; Repo, T.; Pyykkö, P.; Rieger, B. Molecular Tweezers for Hydrogen: Synthesis, Characterization, and Reactivity. J. Am. Chem. Soc. 2008, 130, 14117-14119.

(8) For reviews on FLP chemistry, see: (a) Topics in Current Chemistry; Erker, G., Stephan, D. W., Eds.; Springer-Verlag, 2013; Vols. 
332 and 334. (b) Stephan, D. W.; Erker, G. Frustrated Lewis Pair Chemistry : Development and Perspectives. Angew. Chem., Int. Ed. 2015, 54, 6400-6441. (c) Stephan, D. W. Frustrated Lewis Pairs. J. Am. Chem. Soc. 2015, 137, 10018-10032. (d) Stephan, D. W. Frustrated Lewis Pairs: From Concept to Catalysis. Acc. Chem. Res. 2015, 48, 306316. (e) Stephan, D. W. The Broadening Reach of Frustrated Lewis Pair Chemistry. Science 2016, 354, aaf7229-aaf7229. (f) Jupp, A. R.; Stephan, D. W. New Directions for Frustrated Lewis Pair Chemistry. Trends in Chemistry 2019, 1, 35-48.

(9) For reviews on FLP-type catalytic hydrogenations, see: (a) Stephan, D. W.; Erker, G. Frustrated Lewis Pairs: Metal-free Hydrogen Activation and More. Angew. Chem., Int. Ed. 2010, 49, 4676. (b) Stephan, D. W.; Greenberg, S.; Graham, T. W.; Chase, P.; Hastie, J. J.; Geier, S. J.; Farrell, J. M.; Brown, C. C.; Heiden, Z. M.; Welch, G. C.; Ullrich, M. Metal-Free Catalytic Hydrogenation of Polar Substrates by Frustrated Lewis Pairs. Inorg. Chem. 2011, 50, 1233812348. (c) Stephan, D. W.; Erker, G. Frustrated Lewis Pair Mediated Hydrogenations. Topics in Current Chemistry; Springer: Berlin, 2013; pp 85-110. (d) Sumerin, V.; Chernichenko, K.; Schulz, F.; Leskelä, M.; Rieger, B.; Repo, T. Amine-Borane Mediated Metal-Free Hydrogen Activation and Catalytic Hydrogenation. Topics in Current Chemistry; Springer: Berlin, 2012; pp 111-155. (e) Paradies, J. Metal-Free Hydrogenation of Unsaturated Hydrocarbons Employing Molecular Hydrogen. Angew. Chem., Int. Ed. 2014, 53, 3552-3557. (f) Hounjet, L. J.; Stephan, D. W. Hydrogenation by Frustrated Lewis Pairs: Main Group Alternatives to Transition Metal Catalysts? Org. Process Res. Dev. 2014, 18, 385-391. (g) Scott, D. J.; Fuchter, M. J.; Ashley, A. E. Designing Effective 'Frustrated Lewis Pair' Hydrogenation Catalysts. Chem. Soc. Rev. 2017, 46, 5689-5700. (h) Paradies, J. From Structure to Novel Reactivity in Frustrated Lewis Pairs. Coord. Chem. Rev. 2019, 380, 170-183. (i) Lam, J.; Szkop, K. M.; Mosaferi, E.; Stephan, D. W. FLP Catalysis: Main Group Hydrogenations of Organic Unsaturated Substrates. Chem. Soc. Rev. 2019, 48, 3592-3612. (j) Paradies, J. Mechanisms in Frustrated Lewis Pair-Catalyzed Reactions. Eur. J. Org. Chem. 2019, 2019, 283-294.

(10) For development of water-tolerant FLP catalysts, see: (a) Mahdi, T.; Stephan, D. W. Enabling Catalytic Ketone Hydrogenation by Frustrated Lewis Pairs. J. Am. Chem. Soc. 2014, 136, 15809-15812. (b) Scott, D. J.; Fuchter, M. J.; Ashley, A. E. Nonmetal Catalyzed Hydrogenation of Carbonyl Compounds. J. Am. Chem. Soc. 2014, 136, 15813-15816. (c) Gyömöre, Á; Bakos, M.; Földes, T.; Pápai, I.; Domján, A.; Soós, T. Moisture-Tolerant Frustrated Lewis Pair Catalyst for Hydrogenation of Aldehydes and Ketones. ACS Catal. 2015, 5 , 5366-5372. (d) Scott, D. J.; Simmons, T. R.; Lawrence, E. J.; Wildgoose, G. G.; Fuchter, M. J.; Ashley, A. E. Facile Protocol for Water-Tolerant "Frustrated Lewis Pair"-Catalyzed Hydrogenation. ACS Catal. 2015, 5, 5540-5544. (e) Fasano, V.; Radcliffe, J. E.; Ingleson, M. J. $\mathrm{B}\left(\mathrm{C}_{6} \mathrm{~F}_{5}\right)_{3}$-Catalyzed Reductive Amination Using Hydrosilanes. ACS Catal. 2016, 6, 1793-1798. (f) Scott, D. J.; Phillips, N. A.; Sapsford, J. S.; Deacy, A. C.; Fuchter, M. J.; Ashley, A. E. Versatile Catalytic Hydrogenation Using A Simple Tin(IV) Lewis Acid. Angew. Chem., Int. Ed. 2016, 55, 14738-14742. (g) Dorkó, É.; Szabó, M.; Kótai, B.; Pápai, I.; Domján, A.; Soós, T. Expanding the Boundaries of Water-Tolerant Frustrated Lewis Pair Hydrogenation: Enhanced Back Strain in the Lewis Acid Enables the Reductive Amination of Carbonyls. Angew. Chem., Int. Ed. 2017, 56, 9512-9516. (h) Sapsford, J. S.; Scott, D. J.; Allcock, N. J.; Fuchter, M. J.; Tighe, C. J.; Ashley, A. E. Direct Reductive Amination of Carbonyl Compounds Catalyzed by a Moisture Tolerant Tin(IV) Lewis Acid. Adv. Synth. Catal. 2018, 360, 1066-1071. (i) Hoshimoto, Y.; Kinoshita, T.; Hazra, S.; Ohashi, M.; Ogoshi, S. Main-Group-Catalyzed Reductive Alkylation of Multiply Substituted Amines with Aldehydes Using $\mathrm{H}_{2}$. J. Am. Chem. Soc. 2018, 140, 7292-7300. (j) Fasano, V.; LaFortune, J. H. W.; Bayne, J. M.; Ingleson, M. J.; Stephan, D. W. Air- and Water-Stable Lewis Acids: Synthesis and Reactivity of P-Trifluoromethyl Electrophilic Phosphonium Cations. Chem. Commun. 2018, 54, 662-665. (k) Fasano, V.; Ingleson, M. J. Recent Advances in Water-Tolerance in Frustrated Lewis Pair Chemistry. Synthesis 2018, 50, 1783-1795.
(11) For review articles, see: (a) Chen, D.; Klankermayer, J. Frustrated Lewis Pairs: From Dihydrogen Activation to Asymmetric Catalysis. Top. Curr. Chem. 2013, 334, 1-26. (b) Feng, X.; Du, H. Metal-Free Asymmetric Hydrogenation and Hydrosilylation Catalyzed by Frustrated Lewis Pairs. Tetrahedron Lett. 2014, 55, 6959-6964. (c) Shi, L.; Zhou, Y.-G. Enantioselective Metal-Free Hydrogenation Catalyzed by Chiral Frustrated Lewis Pairs. ChemCatChem 2015, 7, 54-56. (d) Paradies, J. Chiral Borane-Based Lewis Acids for Metal Free Hydrogenations. Topics in Organometallic Chemistry; Springer International Publishing, 2018; pp 193-216. (e) Meng, W.; Feng, X.; Du, H. Frustrated Lewis Pairs Catalyzed Asymmetric Metal-Free Hydrogenations and Hydrosilylations. Acc. Chem. Res. 2018, 51, 191-201. (f) Meng, W.; Feng, X.; Du, H. Asymmetric Catalysis with Chiral Frustrated Lewis Pairs. Chin. J. Chem. 2020, 38, 625-634.

(12) (a) Chen, D.; Klankermayer, J. Metal-Free Catalytic Hydrogenation of Imines with Tris(Perfluorophenyl)Borane. Chem. Commun. 2008, 2130-2131. (b) Chen, D.; Wang, Y.; Klankermayer, J. Enantioselective Hydrogenation with Chiral Frustrated Lewis Pairs. Angew. Chem., Int. Ed. 2010, 49, 9475-9478. (c) Ghattas, G.; Chen, D.; Pan, F.; Klankermayer, J. Asymmetric Hydrogenation of Imines with a Recyclable Chiral Frustrated Lewis Pair Catalyst. Dalton Trans. 2012, 41, 9026-9028.

(13) (a) Parks, D. J.; von H. Spence, R. E.; Piers, W. E. Bis(Pentafluorophenyl)Borane: Synthesis, Properties, and Hydroboration Chemistry of a Highly Electrophilic Borane Reagent. Angew. Chem., Int. Ed. Engl. 1995, 34, 809-811. (b) Parks, D. J.; Piers, W. E.; Yap, G. P. a. Synthesis, Properties, and Hydroboration Activity of the Highly Electrophilic Borane Bis(Pentafluorophenyl)Borane. Organometallics 1998, 17, 5492-5503. (c) Patrick, E. A.; Piers, W. E. TwentyFive Years of Bis-Pentafluorophenyl Borane: A Versatile Reagent for Catalyst and Materials Synthesis. Chem. Commun. 2020, 56, 841-853.

(14) Sumerin, V.; Chernichenko, K.; Nieger, M.; Leskelä, M.; Rieger, B.; Repo, T. Highly Active Metal-Free Catalysts for Hydrogenation of Unsaturated Nitrogen-Containing Compounds. Adv. Synth. Catal. 2011, 353, 2093-2110.

(15) Lindqvist, M.; Borre, K.; Axenov, K.; Kótai, B.; Nieger, M.; Leskela, M.; Pápai, I.; Repo, T. Chiral Molecular Tweezers: Synthesis and Reactivity in Asymmetric Hydrogenation. J. Am. Chem. Soc. 2015, 137, 4038-4041.

(16) Liu, Y.; Du, H. Chiral Dienes as "Ligands" for Borane-Catalyzed Metal-Free Asymmetric Hydrogenation of Imines. J. Am. Chem. Soc. 2013, 135, 6810-6813.

(17) Wei, S.; Du, H. A Highly Enantioselective Hydrogenation of Silyl Enol Ethers Catalyzed by Chiral Frustrated Lewis Pairs. J. Am. Chem. Soc. 2014, 136, 12261-12264.

(18) (a) Zhang, Z.; Du, H. Cis-Selective and Highly Enantioselective Hydrogenation of 2,3,4-Trisubstituted Quinolines. Org. Lett. 2015, 17, 2816-2819. (b) Zhang, Z.; Du, H. Enantioselective Metal-Free Hydrogenations of Disubstituted Quinolines. Org. Lett. 2015, 17, 6266-6269. (c) Zhang, Z.; Du, H. A Highly cis-Selective and Enantioselective Metal-Free Hydrogenation of 2,3-Disubstituted Quinoxalines. Angew. Chem., Int. Ed. 2015, 54, 623-626. (d) Wei, S.; Feng, X.; Du, H. A Metal-Free Hydrogenation of 3-Substituted 2H-1,4Benzoxazines. Org. Biomol. Chem. 2016, 14, 8026-8029.

(19) Tu, X.; Zeng, N.; Li, R.; Zhao, Y.; Xie, D.; Peng, Q.; Wang, X. C $2^{-}$ Symmetric Bicyclic Bisborane Catalysts: Kinetic or Thermodynamic Products of a Reversible Hydroboration of Dienes. Angew. Chem., Int. Ed. 2018, 57, 15096-15100.

(20) (a) Li, X.; Tian, J.; Liu, N.; Tu, X.; Zeng, N.; Wang, X. SpiroBicyclic Bisborane Catalysts for Metal-Free Chemoselective and Enantioselective Hydrogenation of Quinolines. Angew. Chem., Int. Ed. 2019, 58, 4664-4668. (b) Tian, J.; Yang, Z.; Liang, X.; Liu, N.; Hu, C.; $\mathrm{Tu}, \mathrm{X}$.; Li, X.; Wang, X. Borane-Catalyzed Chemoselective and Enantioselective Reduction of 2-Vinyl-Substituted Pyridines. Angew. Chem., Int. Ed. 2020, 59, 18452-18456.

(21) Gao, B.; Feng, X.; Meng, W.; Du, H. Asymmetric Hydrogenation of Ketones and Enones with Chiral Lewis Base Derived Frustrated Lewis Pairs. Angew. Chem., Int. Ed. 2020, 59, 4498-4504. 
(22) For selected contributions, see: (a) Hermeke, J.; Mewald, M.; Oestreich, M. Experimental Analysis of the Catalytic Cycle of the Borane-Promoted Imine Reduction with Hydrosilanes: Spectroscopic Detection of Unexpected Intermediates and a Refined Mechanism. J. Am. Chem. Soc. 2013, 135, 17537-17546. (b) Süsse, L.; Hermeke, J.; Oestreich, M. The Asymmetric Piers Hydrosilylation. J. Am. Chem. Soc. 2016, 138, 6940-6943. (c) Mercea, D. M.; Howlett, M. G.; Piascik, A. D.; Scott, D.J.; Steven, A.; Ashley, A. E.; Fuchter, M. J. Enantioselective reduction of $\mathrm{N}$-alkyl ketimines with frustrated Lewis pair catalysis using chiral borenium ions. Chem. Commun. 2019, 55, 7077-7080. (d) Liu, X.; Wang, Q.; Han, C.; Feng, X.; Du, H. Chiral Frustrated Lewis Pairs Catalyzed Highly Enantioselective Hydrosilylations of Ketones. Chin. J. Chem. 2019, 37, 663-666. (e) Lundrigan, T.; Welsh, E. N.; Hynes, T.; Tien, C.; Adams, M. R.; Roy, K. R.; Robertson, K. N.; Speed, A. W. H. Enantioselective Imine Reduction Catalyzed by Phosphenium Ions. J. Am. Chem. Soc. 2019, 141, 14083-14088.

(23) For computational mechanistic studies on FLP-type catalytic hydrogenations (not addressing the issue of stereoselectivity), see: (a) Rokob, T. A.; Hamza, A.; Stirling, A.; Pápai, I. On the Mechanism of $\mathrm{B}\left(\mathrm{C}_{6} \mathrm{~F}_{5}\right)_{3}$-Catalyzed Direct Hydrogenation of Imines: Inherent and Thermally Induced Frustration. J. Am. Chem. Soc. 2009, 131, 20292036. (b) Nyhlén, J.; Privalov, T. On the Possibility of Catalytic Reduction of Carbonyl Moieties with Tris(Pentafluorophenyl)Borane and $\mathrm{H}_{2}$ : A Computational Study. Dalton Trans. 2009, 29, 5780-5786. (c) Privalov, T. The Role of Amine- $\mathrm{B}\left(\mathrm{C}_{6} \mathrm{~F}_{5}\right)_{3}$ Adducts in the Catalytic Reduction of Imines with $\mathrm{H}_{2}$ : A Computational Study. Eur. J. Inorg. Chem. 2009, 2009, 2229-2237. (d) Li, H.; Zhao, L.; Lu, G.; Huang, F.; Wang, Z.-X. Catalytic Metal-Free Ketone Hydrogenation: A Computational Experiment. Dalton Trans. 2010, 39, 5519-5526. (e) Zhao, L.; Li, H.; Lu, G.; Huang, F.; Zhang, C.; Wang, Z.-X. Metal-Free Catalysts for Hydrogenation of Both Small and Large Imines: A Computational Experiment. Dalton Trans. 2011, 40, 1929-1937. (f) Zhao, L.; Lu, G.; Huang, F.; Wang, Z.-X. A Computational Experiment to Study Hydrogenations of Various Unsaturated Compounds Catalyzed by a Rationally Designed Metal-Free Catalyst. Dalton Trans. 2012, 41, 4674-4684. (g) Chernichenko, K.; Madarász, Á.; Pápai, I.; Nieger, M.; Leskelä, M.; Repo, T. A Frustrated-Lewis-Pair Approach to Catalytic Reduction of Alkynes to Cis-Alkenes. Nat. Chem. 2013, 5, 718-723. (h) Wang, Z.-X.; Zhao, L.; Lu, G.; Li, H. X.; Huang, F. Computational Design of Metal-Free Molecules for Activation of Small Molecules, Hydrogenation, and Hydroamination. Top. Curr. Chem. 2012, 332, 231-266. (i) Zhao, J.; Wang, G.; Li, S. Mechanistic Insights into the Full Hydrogenation of 2,6-Substituted Pyridine Catalyzed by the Lewis Acid $\mathrm{C}_{6} \mathrm{~F}_{5}\left(\mathrm{CH}_{2}\right)_{2} \mathrm{~B}\left(\mathrm{C}_{6} \mathrm{~F}_{5}\right)_{2}$. Dalton Trans. 2015, 44, 9200-9208. (j) Das, S.; Pati, S. K. On the Mechanism of Frustrated Lewis Pair Catalysed Hydrogenation of Carbonyl Compounds. Chem. - Eur. J. 2017, 23, 1078-1085. (k) Heshmat, M.; Privalov, T. Carbonyl Activation by Borane Lewis Acid Complexation: Transition States of $\mathrm{H}_{2}$ Splitting at the Activated Carbonyl Carbon Atom in a Lewis Basic Solvent and the Proton-Transfer Dynamics of the Boroalkoxide Intermediate. Chem. - Eur. J. 2017, 23, 9098-9113. (1) Mane, M. V.; Vanka, K. Less Frustration, More Activity-Theoretical Insights into Frustrated Lewis Pairs for Hydrogenation Catalysis. ChemCatChem 2017, 9, 3013-3022. (m) Heshmat, M.; Privalov, T. Computational Elucidation of a Role That Brønsted Acidification of the Lewis AcidBound Water Might Play in the Hydrogenation of Carbonyl Compounds with $\mathrm{H}_{2}$ in Lewis Basic Solvents. Chem. - Eur. J. 2017, 23, 11489-11493. (n) Heshmat, M.; Privalov, T. Theory-Based Extension of the Catalyst Scope in the Base-Catalyzed Hydrogenation of Ketones: RCOOH-Catalyzed Hydrogenation of Carbonyl Compounds with $\mathrm{H}_{2}$ Involving a Proton Shuttle. Chem. - Eur. J. 2017, 23, 18193-18202. (o) Das, S.; Pati, S. K. Unravelling the Mechanism of Tin-Based Frustrated Lewis Pair Catalysed Hydrogenation of Carbonyl Compounds. Catal. Sci. Technol. 2018, 8, 5178-5189.

(24) For recent reviews on concepts and challenges in computing stereoselectivities, see: (a) Hopmann, K. H. Quantum Chemical Studies of Asymmetric Reactions: Historical Aspects and Recent Examples. Int. J. Quantum Chem. 2015, 115, 1232-1249. (b) Peng, Q.; Duarte, F.; Paton, R. S. Computing Organic Stereoselectivity-from
Concepts to Quantitative Calculations and Predictions. Chem. Soc. Rev. 2016, 45, 6093-6107. (c) Krenske, E. H. Challenges in Predicting Stereoselectivity. In Applied Theoretical Organic Chemistry; Tantillo, D. J., Ed.; World Scientific: New Jersey, 2018; pp 583-604. (d) Gridnev, I. D.; Dub, P. A. Enantioselection in Asymmetric Catalysis; CRC Press: Boca Raton, 2017.

(25) For a detailed computational analysis of $\mathrm{H}_{2}$ activation pathways with the im/ $\mathbf{2}$ and $\mathbf{P} / \mathbf{2}$ pairs, see the SI (section 2.1).

(26) Computed proton affinities of $\mathrm{P}^{\mathrm{t}} \mathrm{Bu}_{3}$ and $\mathrm{im}$ are -277.5 and $-231.7 \mathrm{kcal} / \mathrm{mol}$, respectively. These values are obtained as solution phase Gibbs free energies of base $\rightarrow$ base $\mathrm{H}^{+}$reactions.

(27) For a detailed comparison of the energetics of the two catalytic cycles, see the SI (section 2.2).

(28) For conformational analysis of borohydride $2 \mathrm{H}^{-}$, see the SI (section 2.3).

(29) For details of the conformational analysis carried out for the $\mathrm{imH}^{+} / 2 \mathrm{H}^{-}$ion pair intermediate, see the SI (section 2.4).

(30) For related studies, see, for example: (a) Rokob, T. A.; Hamza, A.; Pápai, I. Rationalizing the Reactivity of Frustrated Lewis Pairs: Thermodynamics of $\mathrm{H}_{2}$ Activation and the Role of Acid-Base Properties. J. Am. Chem. Soc. 2009, 131, 10701-10710. (b) Schulz, F.; Sumerin, V.; Heikkinen, S.; Pedersen, B.; Wang, C.; Atsumi, M.; Leskelä, M.; Repo, T.; Pyykkö, P.; Petry, W.; Rieger, B. Molecular Hydrogen Tweezers: Structure and Mechanisms by Neutron Diffraction, NMR, and Deuterium Labeling Studies in Solid and Solution. J. Am. Chem. Soc. 2011, 133, 20245-20257. (c) Zaher, H.; Ashley, A. E.; Irwin, M.; Thompson, A. L.; Gutmann, M. J.; Krämer, T.; O'Hare, D. Structural and Theoretical Studies of Intermolecular Dihydrogen Bonding in $\left[\left(\mathrm{C}_{6} \mathrm{~F}_{5}\right)_{2}\left(\mathrm{C}_{6} \mathrm{Cl}_{5}\right) \mathrm{B}\right]-\mathrm{H} \cdots \mathrm{H}-[\mathrm{TMP}]$. Chem. Commun. 2013, 49, 9755-9757. (d) Zhivonitko, V. V.; Sorochkina, K.; Chernichenko, K.; Kótai, B.; Földes, T.; Pápai, I.; Telkki, V.-V.; Repo, T.; Koptyug, I. Nuclear Spin Hyperpolarization with Ansa-Aminoboranes: A Metal-Free Perspective for Parahydrogen-Induced Polarization. Phys. Chem. Chem. Phys. 2016, 18, 27784-27795.

(31) For the estimation of barriers relevant to the interconversion of $\mathrm{imH}^{+} / 2 \mathrm{H}^{-}$isomers, see the SI (section 2.4).

(32) For computational studies examining the role of stabilizing noncovalent interactions in TM-catalyzed stereoselective hydrogenations, see: (a) Hopmann, K. H.; Bayer, A. On the Mechanism of Iridium-Catalyzed Asymmetric Hydrogenation of Imines and Alkenes: A Theoretical Study. Organometallics 2011, 30, 2483-2497. (b) Václavík, J.; Kuzma, M.; Přech, J.; Kačer, P. Asymmetric Transfer Hydrogenation of Imines and Ketones Using Chiral $\mathrm{Ru}^{\mathrm{II}} \mathrm{Cl}\left(\eta^{6}-\mathrm{p}\right.$ cymene $)[(S, S)-\mathrm{N}-\mathrm{TsDPEN}]$ as a Catalyst: A Computational Study. Organometallics 2011, 30, 4822-4829. (c) Wang, T.; Zhuo, L.-G.; Li, Z.; Chen, F.; Ding, Z.; He, Y.; Fan, Q.-H.; Xiang, J.; Yu, Z.-X.; Chan, A. S. C. Highly Enantioselective Hydrogenation of Quinolines Using Phosphine-Free Chiral Cationic Ruthenium Catalysts: Scope, Mechanism, and Origin of Enantioselectivity. J. Am. Chem. Soc. 2011, 133, 9878-9891. (d) Pablo, Ó.; Guijarro, D.; Kovács, G.; Lledós, A.; Ujaque, G.; Yus, M. A Versatile Ru Catalyst for the Asymmetric Transfer Hydrogenation of Both Aromatic and Aliphatic Sulfinylimines. Chem. - Eur. J. 2012, 18, 1969-1983. (e) Hopmann, K. H. Iron/ Brønsted Acid Catalyzed Asymmetric Hydrogenation: Mechanism and Selectivity-Determining Interactions. Chem. - Eur. J. 2015, 21, 1002010030. (f) Tutkowski, B.; Kerdphon, S.; Limé, E.; Helquist, P.; Andersson, P. G.; Wiest, O.; Norrby, P.-O. Revisiting the Stereodetermining Step in Enantioselective Iridium-Catalyzed Imine Hydrogenation. ACS Catal. 2018, 8, 615-623. (g) Salomó, E.; Gallen, A.; Sciortino, G.; Ujaque, G.; Grabulosa, A.; Lledós, A.; Riera, A.; Verdaguer, X. Direct Asymmetric Hydrogenation of N-Methyl and N-Alkyl Imines with an Ir(III)H Catalyst. J. Am. Chem. Soc. 2018, 140, 16967-16970. (h) Chen, J.; Gridnev, I. D. Size is Important: Artificial Catalyst Mimics Behaviour of Natural Enzymes. iScience 2020, 23, 100960.

(33) For a selection of related studies on TM-catalyzed stereoselective hydrogenation of other substrates, see: (a) Hopmann, K. H. CobaltBis(Imino)Pyridine-Catalyzed Asymmetric Hydrogenation: Electronic Structure, Mechanism, and Stereoselectivity. Organometallics 2013, 32, 
6388-6399. (b) Dub, P. a.; Henson, N. J.; Martin, R. L.; Gordon, J. C. Unravelling the Mechanism of the Asymmetric Hydrogenation of Acetophenone by $\left[\mathrm{RuX}_{2}\right.$ (Diphosphine)(1,2-Diamine)] Catalysts. J. Am. Chem. Soc. 2014, 136, 3505-3521. (c) Nakatsuka, H.; Yamamura, T.; Shuto, Y.; Tanaka, S.; Yoshimura, M.; Kitamura, M. Mechanism of Asymmetric Hydrogenation of Aromatic Ketones Catalyzed by a Combined System of $\mathrm{Ru}\left(\pi-\mathrm{CH}_{2} \mathrm{C}\left(\mathrm{CH}_{3}\right) \mathrm{CH}_{2}\right)_{2}(\mathrm{Cod})$ and the Chiral $\mathrm{Sp}^{2} \mathrm{~N} / \mathrm{Sp}^{3} \mathrm{NH}$ Hybrid Linear N4 Ligand Ph-BINAN-H-Py. J. Am. Chem. Soc. 2015, 137, 8138-8149. (d) Dub, P. A.; Gordon, J. C. The Mechanism of Enantioselective Ketone Reduction with Noyori and Noyori-Ikariya Bifunctional Catalysts. Dalton Trans. 2016, 45, 67566781. (e) Nakane, S.; Yamamura, T.; Manna, S. K.; Tanaka, S.; Kitamura, M. Mechanistic Study of the Ru-Catalyzed Asymmetric Hydrogenation of Nonchelatable and Chelatable Tert-Alkyl Ketones Using the Linear Tridentate $S \mathrm{p}^{3} \mathrm{P} / \mathrm{Sp}^{3} \mathrm{NH} / \mathrm{Sp}^{2} \mathrm{~N}$-Combined Ligand $\mathrm{PN}(\mathrm{H}) \mathrm{N}$ : RuNH- and RuNK-Involved Dual Catalytic Cycle. ACS Catal. 2018, 8, 11059-11075.

(34) For structures of all HT transition states in the reaction with borane 2 and related structural analysis, see the SI (section 2.5).

(35) The HT step of the catalytic cycle of im hydrogenation is an irreversible process. For the reaction with borane 2 , the $\mathbf{a m}+\mathbf{2}$ product state is predicted to be $16.1 \mathrm{kcal} / \mathrm{mol}$ below the most favored $\mathrm{imH}^{+}$/ $2 \mathrm{H}$.

(36) The nearly quantitative agreement between computed and observed ee values is no doubt fortuitous and cannot be regarded as a measure of accuracy of the applied computational methodology.

(37) For structures of all HT transition states in the reaction with borane 3 and related structural analysis, see the SI (section 2.6).

(38) For structures of all HT transition states in the reaction with borane 1 and related structural analysis, see the SI (section 2.7).

(39) The RDG data were computed by using the NCIPLOT program: (a) Johnson, E. R.; Keinan, S.; Mori-Sánchez, P.; Contreras-García, J.; Cohen, A. J.; Yang, W. Revealing Noncovalent Interactions. J. Am. Chem. Soc. 2010, 132, 6498-6506. (b) Contreras-García, J.; Johnson, E. R.; Keinan, S.; Chaudret, R.; Piquemal, J.-P.; Beratan, D. N.; Yang, W. NCIPLOT: A Program for Plotting Non-Covalent Interaction Regions. J. Chem. Theory Comput. 2011, 7, 625-632.

(40) For details on the reaction with the simplified borane, see the SI (section 2.8).

(41) For details on computational analysis for hydrogenation reactions with boranes $\mathbf{2}-\mathrm{F}, \mathbf{2}-\mathrm{CF}_{3}, \mathbf{2}-\mathrm{CH}_{3},{ }^{-}{ }^{-} \mathbf{B u}$, and $\mathbf{2}$-ant, see the SI (section 2.9).

(42) For the influence of various substituents on the strength of $\mathrm{CH} \cdots \pi$ interaction, see: Karthikeyan, S.; Ramanathan, V.; Mishra, B. K. Influence of the Substituents on the $\mathrm{CH} \cdots \pi$ Interaction: BenzeneMethane Complex. J. Phys. Chem. A 2013, 117, 6687-6694. 